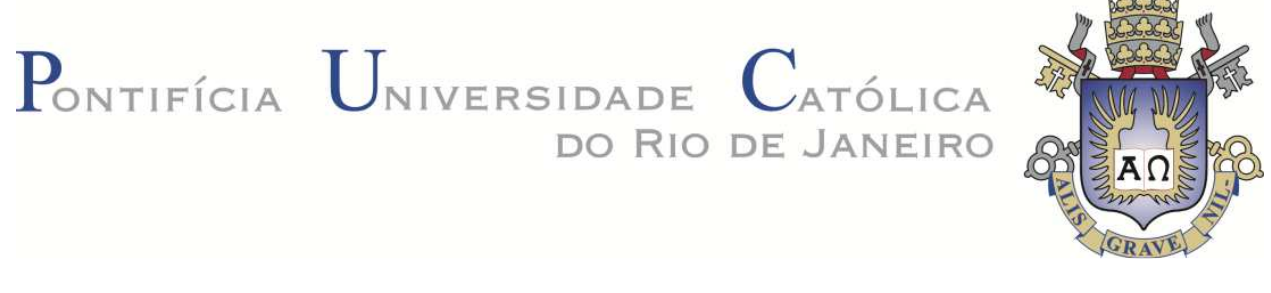

Rogério Cortez Brito Leite Póvoa

Otimização Estrutural de Aglomerados de Carbono por Programação Genética

Dissertação de Mestrado

Dissertação apresentada ao Programa de Pósgraduação em Engenharia Elétrica da PUC-Rio como requisito parcial para obtenção do título de Mestre em Engenharia Elétrica.

Orientador: Prof. Marco Aurélio C. Pacheco

Co-Orientador: Prof. Bruno Araújo C. Horta 


\section{Otimização Estrutural de Aglomerados de Carbono por Programação Genética}

Dissertação apresentada como requisito parcial para obtenção do grau de Mestre pelo Programa de Pós-Graduação em Engenharia Elétrica do Departamento de Engenharia Elétrica do Centro Técnico Científico da PUC-Rio. Aprovada pela Comissão Examinadora abaixo assinada

Prof. Marco Aurélio Cavalcanti Pacheco Orientador Departamento de Engenharia Elétrica - PUC-Rio

Prof. Bruno Araújo Cautiero Horta Co-Orientador

Departamento de Engenharia Elétrica - PUC-Rio

Profa. Patrícia Lustoza de Souza Centro de Estudos em Telecomunicações - PUC-Rio

Prof. Juan Guillermo Lazo Lazo Departamento de Engenharia Elétrica - PUC-Rio

Prof. Omar Paranaiba Vilela Neto UFMG

Prof. Douglas Mota Dias Departamento de Engenharia Elétrica - PUC-Rio

Prof. Alain André Quivy USP

Prof. José Eugênio Leal Coordenador Setorial do Centro Técnico Científico

Rio de Janeiro, 10 de abril de 2013 
Todos os direitos reservados. É proibida a reprodução total o parcial do trabalho sem autorização da universidade, do autor e do orientador.

\section{Rogério Cortez Brito Leite Póvoa}

Graduou-se em Engenharia de Computação na Pontifícia Universidade Católica do Rio de Janeiro.

Ficha Catalográfica

Póvoa, Rogério Cortez Brito Leite

Otimização Estrutural de Aglomerados de Carbono por Programação Genética / Rogério Cortez Brito Leite Póvoa; orientador: Marco Aurélio C. Pacheco ; co-orientador: Bruno Araújo C. Horta. - 2013.

76 f. : il. (color.) ; $30 \mathrm{~cm}$

Dissertação (mestrado)-Pontifícia Universidade Católica do Rio de Janeiro, Departamento de Engenharia Elétrica, 2013.

Inclui bibliografia.

1. Engenharia elétrica - Teses. 2. Computação Evolucionária. 3. Aglomerados atômicos e moleculares. 4. Otimização estrutural de aglomerados de carbono por Programação Genética. I. Pacheco, Marco Aurélio C. II. Horta, Bruno Araújo C. III. Pontifícia Universidade Católica do Rio de Janeiro. Departamento de Engenharia Elétrica. IV. Título. 
Aos meus pais, Rodolpho Antonio e Flávia Regina, aos meus irmãos, Marcos e Sílvia Maria, e à minha namorada, Franciane. 


\section{Agradecimentos}

Ao CNPq e à PUC-Rio pelos auxílios concedidos, sem os quais este trabalho não poderia ser realizado.

Ao meu orientador, Prof. Marco Aurélio C. Pacheco, e co-orientador, Prof. Bruno Araújo C. Horta, pelos ensinamentos e parceria.

Aos professores, Douglas Dias, Juan Lazo, Omar Paranaiba e Patrícia Lustoza, pelas discussões, conselhos e auxílios.

Aos demais professores pelos ensinamentos.

Aos meus amigos, da PUC-Rio, Adriano Koshiyama, Alan Bontempo, Andres Benjamin, Alexandre Figueira, Harold de Mello Jr., Carlos Augusto Federico, lury Steiner, Manoela Kohler, Marco Aurélio Silva, Rafael Cardoso, Reinaldo Bellini e Thiago Dias, por todas as ajudas prestadas durante o curso de pós-graduação.

Aos meus amigos Bernardo Braga, Gustavo Carbonel, Jeizzon Mendes, Lucas Alves, Luiz Eduardo Santos, Luiz Franklin de Mattos, Marcello Soto, Pedro Altoé, Ricardo Neto, Rodrigo Azevedo, Thiago Esteves, Thiago Morais, Thiago Roldão, Vitor Hugo Conti e Zacarias Filho pelo apoio e incentivo.

Aos demais amigos, que de alguma forma me apoiaram e incentivaram.

À minha namorada Franciane Ribeiro, pelo amor, apoio e incentivo em todos os momentos.

Aos meus pais e irmãos, pelo amor incondicional, apoio e presença constante.

A Deus. 


\section{Resumo}

Póvoa, Rogério Cortez Brito Leite; Pacheco, Marco Aurélio Cavalcanti; Horta, Bruno Araújo Cautiero. Otimização estrutural de aglomerados de carbono por Programação Genética. Rio de Janeiro, 2013. 76 p. Dissertação de Mestrado - Departamento de Engenharia Elétrica, Pontifícia Universidade Católica do Rio de Janeiro.

Esta dissertação investiga o uso da Programação Genética para otimização estrutural de aglomerados de carbono. O objetivo primordial do estudo de cálculos que descrevam as interações de um aglomerado é encontrar o arranjo de átomos que corresponde à menor energia, ou àqueles que possuem energias próximas, já que estes são os candidatos mais prováveis de serem formados. Recentemente, na área da Inteligência Computacional, estudos apresentaram um novo método de otimização, chamado de Otimização por Programação Genética (OPG), com resultados promissores, avaliados em diversos casos de referência. A partir destes resultados, esta pesquisa aplica, de forma inédita, a abordagem OPG em problemas de otimização estrutural de aglomerados. Para fins de comparação, foram realizadas otimizações independentes utilizando o modelo tradicional de Algoritmos Genéticos (AGs). Neste trabalho, foram realizados vários ensaios computacionais utilizando os métodos OPG e AG para otimizar a geometria, ou seja, encontrar a estrutura de menor energia, de aglomerados de carbono de 5 a 25 átomos. Para o cálculo da energia, foi utilizado o potencial de Morse. Os valores das energias encontrados e as geometrias de cada aglomerado foram comparados com casos já publicados na literatura. Os resultados mostraram que, para os aglomerados menores, os dois métodos foram capazes de encontrar os mínimos globais, mas com o aumento do número de átomos, o OPG apresenta resultados superiores ao AG. Quanto ao tempo de execução por avaliação, o AG se mostrou significativamente mais rápido do que o do $\mathrm{OPG}$, devido à sua representação direta das posições dos átomos, de um aglomerado, em um cromossomo. Porém a superioridade dos resultados OPG em relação ao AG indicou que a melhoria na sua implementação poderá ser de grande utilidade na área de simulação de aglomerados atômicos ou moleculares. 


\section{Palavras-chave}

Aglomerados Atômicos ou Moleculares; Algoritmos Genéticos; Computação Evolucionária; Otimização por Programação Genética; Nanotecnologia Computacional. 


\section{Abstract}

Póvoa, Rogério Cortez Brito Leite; Pacheco, Marco Aurélio Cavalcanti (Advisor); Horta, Bruno Araújo Cautiero. Structure optimization of carbon clusters by Genetic Programming. Rio de Janeiro, 2013. 76 p. MSc. Dissertation - Departamento de Engenharia Elétrica, Pontifícia Universidade Católica do Rio de Janeiro.

This dissertation investigates the use of Genetic Programming for the structural optimization of carbon clusters. The main objective concerning computations that describe the interactions of a cluster is to find the arrangements of atoms corresponding to the lowest energy, since these are the most likely candidates to be formed. It has been recently introduced in the area of Computational Intelligence a new optimization method, called Optimization by Genetic Programming (OGP), showing promising results for several benchmark cases. Based on these results, the present work aimed at the application of OGP for the geometry optimization of carbon clusters. For comparison purposes, independent optimizations using the standard genetic algorithm (GA) approach were carried out. Several optimization trials were performed using both GA and OGP in order to find the best geometries of carbon clusters with size ranging from 5 to 25 atoms. The energy was calculated using the Morse potential. Resulting energies and geometries were compared to previously published results. Both GA and OGP were able to find the global minimum for the smaller clusters. However, upon increasing the number of atoms, the OGP presented better results compared to the GA. Concerning the execution time for each evaluation, the GA is significantly faster than the OGP due to its direct representation of the positions of atoms of a cluster in a chromosome. However, the superiority of the OGP results compared to the GA results suggests that an effort towards the improvement of the implementation of OGP could lead to a very powerful optimization tool to be used by the scientific community. 


\section{Keywords}

Atomic and Molecular Clusters; Genetic Algorithms; Evolutionary Computation; Optimization by Genetic Programming; Computational Nanotechnology. 


\section{Sumário}

1 Introdução 19

1.1 Motivação 19

$\begin{array}{lll}1.2 & \text { Objetivo } & 20\end{array}$

1.3 Etapas de execução 20

1.4 Contribuições 21

1.5 Organização da dissertação 22

2 Computação Evolucionária 23

2.1 Introdução 23

2.2 Algoritmos Genéticos 23

2.2.1 Representação 25

2.2.2 Avaliação 26

2.2.3 Operadores genéticos 26

2.2.4 Parâmetros da evolução 28

2.3 Programação Genética 29

2.4 Programação Genética Multigênica 35

2.5 Otimização por Programação Genética 37

3 Aglomerados atômicos e moleculares 42

3.1 Introdução 42

3.2 Otimização estrutural de aglomerados 42

3.3 Otimização estrutural de aglomerados de carbono 43

3.4 Otimização estrutural de aglomerados por Algoritmos

Genéticos $\quad 45$

4 Otimização estrutural de aglomerados de carbono por

Programação Genética $\quad 48$

4.1 Introdução 48

4.2 Metodologia 48

4.2.1 Algoritmo Genético 49 
4.2.2 Otimização por Programação Genética 50

4.3 Resultados e discussões 51

4.3.1 Potencial de Morse 51

4.3.2 Resultados das otimizações 53

4.3.3 Estrutura dos aglomerados 63

$\begin{array}{lll}\text { 4.3.4 Tempo de simulação } & 66\end{array}$

5 Conclusão e Trabalhos Futuros $\quad 69$

$\begin{array}{ll}\text { Referências Bibliográficas } & 71\end{array}$

$\begin{array}{ll}\text { A Wilcoxon Signed Rank } & 75\end{array}$ 


\section{Lista de Figuras}

2.1 Estrutura básica de um Algoritmo Genético.

2.2 Representação do programa " $x^{2}+y$ ": (a) Representação sob a forma de árvore; (b) forma pré-fixada.

2.3 Operador genético de Reprodução para PG. O indivíduo é copiado para a próxima geração.

2.4 Operador genético de Cruzamento para PG. O cruzamento entre os indivíduos P1 e P2 geram os indivíduos P3 e P4.

2.5 Operador genético de Mutação para PG. Uma subárvore aleatória substitui a subárvore que está abaixo de um ponto selecionado.

2.6 Operador genético de Permutação para PG. Os elementos $\mathrm{x}$ e $\mathrm{y}$, da subtração, foram permutados pelo operador genético.

2.7 Operador genético de Edição para PG. O programa foi simplificado pelo operador genético.

2.8 Operador genético de Encapsulamento para PG. A função " $F_{0}=(x+x)$ " foi encapsulada pelo operador genético.

2.9 Exemplo de um indivíduo multigênico [25].

2.10 Operação de cruzamento de baixo nível em um indivíduo multigênico [25].

2.11 Operação de mutação em um indivíduo multigênico [25]. 36

2.12 Operação de cruzamento de alto nível em um indivíduo multigênico [25].

2.13 Exemplificação do algoritmo PMA [25].

2.14 Solução trivial (a) e não trivial (b) [26].

2.15 Exemplo da distinção entre as soluções encontradas por PMA e OPG [26].

2.16 Pseudo-código do método OPG. 
3.1 Curvas do potencial de Morse para diferentes valores de $\rho_{0}$. Cada curva possui uma legenda referente ao seu valor de $\rho_{0}$. A figura foi reproduzida da Ref. [9].

3.2 Simplificação da superfície de energia por degraus. 46

4.1 Cromossomo de um aglomerado atômico para o AG. 49

4.2. Cromossomo de um aglomerado atômico para o OPG. 50

4.3 Gráfico da energia dos aglomerados, variando o número de átomos de 5 a 25, pelo $A G, O P G$ e a energia mínima global (EMG), para $\rho_{0}=3$. As energias estão em $\epsilon$.

4.4 Gráfico da energia dos aglomerados, variando o número de átomos de 5 a 25, pelo $A G, O P G$ e a energia mínima global (EMG), para $\rho_{0}=6$. As energias estão em $\epsilon$.

4.5 Gráfico da energia dos aglomerados, variando o número de átomos de 5 a 25, pelo $A G, O P G$ e a energia mínima global (EMG), para $\rho_{0}=10$. As energias estão em $\epsilon$.

4.6 Gráfico da energia dos aglomerados, variando o número de átomos de 5 a 25, pelo $A G, O P G$ e a energia mínima global (EMG), para $\rho_{0}=14$. As energias estão em $\epsilon$.

4.7 Gráfico da diferença de energias dos aglomerados, variando o número de átomo de $5 \mathrm{a} 25, \operatorname{com} \rho_{0}=3$. As energias estão em $\epsilon$.

4.8 Gráfico da diferença de energias dos aglomerados, variando o número de átomos de 5 a $25, \operatorname{com} \rho_{0}=6$. As energias estão em $\epsilon$.

4.9 Gráfico da diferença de energias dos aglomerados, variando o número de átomos de 5 a 25 , com $\rho_{0}=10$. As energias estão em $\epsilon$.

4.10 Gráfico da diferença de energias dos aglomerados, variando o número de átomos de 5 a 25 , com $\rho_{0}=14$. As energias estão em $\epsilon$.

4.11 Gráficos da ordenação das energias para as dez simulações realizadas pelo $\mathrm{AG}, \operatorname{com} \rho_{0}=3$, para o número de átomos (n) de 5 a 25. As energias estão em $\epsilon$. 
4.12 Gráficos da ordenação das energias para as dez simulações realizadas pelo $\mathrm{AG}$, com $\rho_{0}=6$, para o número de átomos (n) de 5 a 25. As energias estão em $\epsilon$.

4.13 Gráficos da ordenação das energias para as dez simulações realizadas pelo $\mathrm{AG}$, $\operatorname{com} \rho_{0}=10$, para o número de átomos (n) de 5 a 25. As energias estão em $\epsilon$.

4.14 Gráficos da ordenação das energias para as dez simulações realizadas pelo $A G$, $\operatorname{com} \rho_{0}=14$, para o número de átomos (n) de 5 a 25. As energias estão em $\epsilon$.

4.15 Gráficos da ordenação das energias para as dez simulações realizadas pelo OPG, $\operatorname{com} \rho_{0}=3$, para o número de átomos (n) de 5 a 25. As energias estão em $\epsilon$.

4.16 Gráficos da ordenação das energias para as dez simulações realizadas pelo OPG, $\operatorname{com} \rho_{0}=6$, para o número de átomos (n) de 5 a 25. As energias estão em $\epsilon$.

4.17 Gráficos da ordenação das energias para as dez simulações realizadas pelo OPG, com $\rho_{0}=10$, para o número de átomos (n) de 5 a 25. As energias estão em $\epsilon$.

4.18 Gráficos da ordenação das energias para as dez simulações realizadas pelo OPG, com $\rho_{0}=14$, para o número de átomos (n) de 5 a 25. As energias estão em $\epsilon$.

4.19 Aglomerados de carbono, com 6 átomos. (a) aglomerado encontrado pelo OPG, com $\rho_{0}=6$; (b) aglomerado com energia mínima global, com $\rho_{0}=6$.

4.20 Aglomerados de carbono, com 25 átomos. (a) aglomerado encontrado pelo $\mathrm{AG}$, $\operatorname{com} \rho_{0}=10$; (b) aglomerado com energia mínima global, com $\rho_{0}=10$.

4.21 Aglomerados de carbono, com 25 átomos. (a) aglomerado encontrado pelo OPG, com $\rho_{0}=10$; (b) aglomerado com energia mínima global, com $\rho_{0}=10$.

4.22 Tempo médio, em segundos, de execução por avaliação, variando o número de átomos do aglomerado de carbono, para o AG. 
4.23 Tempo médio, em segundos, de execução por avaliação, variando o número de átomos do aglomerado de carbono, para o OPG. 


\section{Lista de Tabelas}

2.1 Parâmetros de controle de um algoritmo de PG.

3.1 Energia mínima global encontrada nas Refs. [9] e [10] para os vários valores de $\rho_{0}$ considerados $(3,6,10$ e 14). As energias estão em $\epsilon$.

4.1 Terminais e funções do OPG. 51

4.2 Principais configurações do OPG. 51

4.3 Resultado do cálculo de energia dos aglomerados ( $E_{\text {calc }}$ ) que apresentaram energia mínima global (EMG) em [10], com $\rho_{0}=3$. As energias estão em $\epsilon$.

4.4 Resultado do cálculo de energia dos aglomerados (Ecalc) que apresentaram energia mínima global (EMG) em [10], com $\rho_{0}=6$. As energias estão em $\epsilon$.

4.5 Resultado do cálculo de energia dos aglomerados (Ecalc) que apresentaram energia mínima global (EMG) em [10], com $\rho_{0}=10$. As energias estão em $\epsilon$.

4.6 Resultado do cálculo de energia do aglomerado (Ecalc) que apresentou energia mínima global (EMG) em [10], com $\rho_{0}=14$. A energia está em $\epsilon$.

4.7 Valor da energia encontrado pelos métodos OPG e AG para cada aglomerado de carbono, com $\rho_{0}$ igual a 3 e 6 . As energias estão em $\epsilon$.

4.8 Valor da energia encontrado pelos métodos OPG e AG para cada aglomerado de carbono, $\operatorname{com} \rho_{0}$ igual a $10 \mathrm{e}$ 14. As energias estão em $\epsilon$.

4.9 Valor da energia mediana encontrada pelos métodos OPG e AG para cada aglomerado de carbono, $\operatorname{com} \rho_{0}$ igual a 3 e 6 . As energias estão em $\epsilon$.

4.10 Valor da mediana da energia encontrada pelos métodos OPG e AG para cada aglomerado de carbono, com $\rho_{0}$ igual a 10 e 14. As energias estão em $\epsilon$. 
4.11 Valor da mediana das medianas das energias encontradas pelos métodos OPG e AG dos aglomerados de carbono, com $\rho_{0}$ igual a 3 e 6 . As energias estão em $\epsilon$.

4.12 Valor da mediana das medianas das energias encontradas pelos métodos OPG e AG dos aglomerados de carbono, com $\rho_{0}$ igual a 10 e 14. As energias estão em $\epsilon$.

4.13 Resultado da comparação entre os métodos AG e OPG, pelo método Wilcoxon Signed Rank.

4.14 RMSD entre os aglomerados com energia mínima global (EMG) e os aglomerados encontrados pelos métodos $A G$ e OPG, para $\rho_{0}=3$.

4.15 RMSD entre os aglomerados com energia mínima global (EMG) e os aglomerados encontrados pelos métodos $A G$ e OPG, para $\rho_{0}=6$.

4.16 RMSD entre os aglomerados com energia mínima global (EMG) e os aglomerados encontrados pelos métodos AG e OPG, para $\rho_{0}=10$.

4.17 RMSD entre os aglomerados com energia mínima global (EMG) e os aglomerados encontrados pelos métodos $A G$ e OPG, para $\rho_{0}=14$. 


\section{Siglas}
AG Algoritmo Genético
$\mathrm{AE} \quad$ Algoritmo Evolucionário
CE Computação Evolucionária
DFT Teoria do Funcional da Densidade
EMG Energia Mínima Global
OPG Otimização por Programação Genética
PG Programação Genética
PGMG Programação Genética Multigênica
PMA Parameter Mapping Approach
RMSD Root Mean Square Deviation 


\section{Introdução}

\section{1}

\section{Motivação}

Um conjunto de átomos, ou moléculas, é chamado de aglomerado atômico, ou molecular. O estudo do comportamento de um aglomerado, e a análise de sua geometria, podem ser um problema de grande complexidade, dependendo do número de átomos, ou moléculas, envolvidos [1]. Esta complexidade se dá pelo grande aumento do número de interações atômicas, com o aumento do número de átomos ou moléculas. O aumento do número de átomos implica em um aumento significativo da dimensionalidade da superfície de energia potencial, tornando a busca do mínimo global um problema extremamente complexo.

Estudos computationais (otimização de geometria, simulação estocástica, simulação determinística, etc.) permitem um melhor entendimento do comportamento de aglomerados, porém o cálculo das interações entre átomos pode exigir um elevado custo computacional dependendo do nível de teoria utilizado. Considerando a otimização de geometria (busca por estados estacionários de baixa energia na superfície de energia potencial), um algoritmo eficaz é aquele que necessita de um número razoavelmente pequeno de iterações para levar a uma solução. Diversas técnicas de Inteligência Computacional têm sido empregadas na área de otimização aplicadas a problemas diversos da engenharia, gerando algoritmos eficientes para problemas cada vez mais complexos [2 - 4].

A utilização de técnicas da Inteligência Computacional como sistema de apoio à Nanotecnologia Computacional é conhecida como "Nanotecnologia Computacional Inteligente", termo utilizado pela primeira vez no trabalho da Ref. [5]. 


\section{2}

\section{Objetivo}

O objetivo desta dissertação é propor e validar a utilização da Programação Genética (PG) como método de otimização estrutural de aglomerados atômicos e moleculares. Pretende-se realizar duas abordagens independentes, com métodos diferentes de otimização, para comparação dos resultados. A primeira abordagem envolve a utilização de Algoritmos Genéticos (AGs), técnica já utilizada na literatura para este tipo de problema [6 - 8]. A segunda abordagem envolve a utilização de um método recente da Programação Genética, chamado de Otimização por Programação Genética (OPG). Pretende-se validar os resultados com benchmarks bem estabelecidos na literatura $[9 ; 10]$.

\section{3}

\section{Etapas de execução}

Este trabalho foi desenvolvido conforme as etapas abaixo:

1. Revisão bibliográfica sobre os fundamentos teóricos de aglomerados atômicos e moleculares.

2. Estudo sobre otimização estrutural de aglomerados atômicos e moleculares.

3. Estudo sobre Computação Evolucionária.

4. Desenvolvimento de um programa para calcular a energia de aglomerados atômicos através do Potencial de Morse. Esta etapa consistiu no desenvolvimento de um programa, em MATLAB, utilizando o potencial de Morse como função para o cálculo da energia de aglomerados atômicos de qualquer tamanho.

5. Desenvolvimento de um programa para otimização estrutural de aglomerados atômicos através de um Algoritmo Genético (AG). Esta etapa consistiu no desenvolvimento de um programa em MATLAB para otimização estrutural, via $A G$, de aglomerados atômicos, utilizando como função objetivo a minimização da 
energia total do sistema, calculada através do potencial de Morse (item anterior).

6. Desenvolvimento de um programa para otimização estrutural de aglomerados atômicos através da Programação Genética (PG). Nesta etapa um programa em MATLAB foi desenvolvido para otimização estrutural, via PG, de aglomerados atômicos, utilizando como função objetivo a minimização da energia total do sistema, calculada através do potencial de Morse (item 4).

7. Análise das energias encontradas. Esta etapa consistiu na análise dos resultados obtidos pelos dois métodos implementados e por resultados da literatura. Os resultados foram comparados através da geração de gráficos e utilização do método Wilcoxon Signed Rank.

8. Análise estrutural dos aglomerados otimizados. Esta etapa consistiu na análise estrutural dos aglomerados otimizados comparando-os com os aglomerados disponíveis na literatura. Os resultados foram comparados através do cálculo do desvio médio quadrático.

9. Análise do tempo de simulação. Esta etapa consistiu na análise do tempo de execução, por avaliação, para os dois métodos de otimização implementados.

\section{4}

\section{Contribuições}

Esta dissertação propôs e desenvolveu a otimização estrutural de aglomerados por Programação Genética. Seus resultados demonstram que este método pode ser utilizado para este tipo de otimização e trabalhos futuros podem trazer benefícios tanto para a área de otimização estrutural de aglomerados atômicos e moleculares, quanto para a área de Métodos de Apoio à Decisão. 


\section{5}

\section{Organização da dissertação}

Esta dissertação está dividida em cinco capítulos adicionais, os quais serão apresentados a seguir:

O capítulo 2 introduz técnicas da computação evolucionária, mais especificamente Algoritmos Genéticos, Programação Genética, Programação Genética Multigênica e Otimização por Programação Genética.

O capítulo 3 apresenta o conceito de aglomerados atômicos e moleculares, bem como, um resumo histórico sobre otimização estrutural de aglomerados.

O capítulo 4 consiste na apresentação do trabalho realizado para otimização estrutural de aglomerados de carbono por Programação Genética.

Por último, o capítulo 5 contém a conclusão e sugestões de trabalhos futuros. 


\section{Computação Evolucionária}

\section{1 \\ Introdução}

A Computação Evolucionária ou Evolutiva (CE) consiste no projeto e/ou análise de algoritmos estocásticos inspirados em princípios da seleção natural de Darwin e suas variações [11]. Segundo este princípio, uma população de indivíduos evolui, ao longo de gerações ou ciclos, pela sobrevivência dos mais aptos. Por sua vez, os algoritmos que compõem a CE são denominados Algoritmos Evolucionários (AEs).

Este capítulo apresenta conceitos sobre AEs. A seção 2.2 aborda o princípio de funcionamento dos Algoritmos Genéticos (AGs), descrevendo suas principais características e seus parâmetros de evolução.

Em seguida, são exibidas as técnicas de Programação Genética (PG) e Programação Genética Multigênica (PGMG). Estas, tradicionalmente, são usadas em problemas de previsão, classificação, ou ainda descoberta de conhecimento, etc. Entretanto, neste trabalho, foram usadas como métodos de otimização. Esta possibilidade de otimizar por PGMG é explicada na última seção do capítulo.

\section{2}

\section{Algoritmos Genéticos}

Essencialmente, Algoritmos Genéticos são métodos de busca e otimização [12 - 16], que têm sua inspiração nos conceitos da teoria de seleção natural das espécies proposta por Darwin. Os sistemas desenvolvidos a partir deste princípio são utilizados para procurar soluções de problemas complexos ou com espaço de soluções (espaço de busca) muito grande, o que os tornam problemas de difícil modelagem e solução quando se aplicam métodos de otimização convencionais, ou programação matemática. 
Estes algoritmos são baseados nos processos genéticos de organismos biológicos para procurar soluções ótimas ou subótimas. Para tanto, procede-se da seguinte maneira: codifica-se um conjunto de possíveis soluções de um problema em uma estrutura chamada de "cromossomo", que é composta por uma cadeia de bits ou caracteres. Estes cromossomos representam indivíduos, que são evoluídos ao longo de várias gerações, de forma similar aos seres vivos, de acordo com os princípios de seleção natural e sobrevivência dos mais aptos, descrito pela primeira vez por Charles Darwin, em seu livro $A$ Origem das Espécies. Emulando estes processos, os Algoritmos Genéticos são capazes de "evoluir" soluções de problemas.

Os cromossomos são então submetidos a um processo evolucionário que envolve avaliação, seleção, cruzamento e mutação. Após vários ciclos de evolução, a população deverá conter indivíduos mais aptos. Os AGs utilizam uma analogia direta deste fenômeno de evolução na natureza, onde cada indivíduo representa uma possível solução para um problema dado. A cada indivíduo atribui-se um valor de adaptação, sua aptidão, que indica o quanto a solução representada por este indivíduo é boa em relação às outras soluções da população, cujo análogo em programação matemática é o resultado da função objetivo. Desta maneira, o termo "população" refere-se ao conjunto de todas as soluções com as quais trabalha o sistema. Aos indivíduos mais adaptados é dada a oportunidade de se reproduzir mediante cruzamentos com outros indivíduos da população, produzindo descendentes com características de ambas as partes.

A mutação também tem um papel significativo no processo evolucionário, ao introduzir alterações aleatórias no cromossomo dos indivíduos, já existentes, e selecionados por este operador. Assim como o DNA dos seres vivos, que sofre modificações aleatórias ao longo da vida (e.g. constante bombardeio de raios cósmicos etc.).

O processo de evolução começa com a criação aleatória dos indivíduos que formarão a população inicial. A partir de um processo de seleção baseado na aptidão de cada indivíduo, são escolhidos os indivíduos para a fase de reprodução, que cria novas soluções utilizando- 
se, para isso, um conjunto de operadores genéticos. Deste modo, a aptidão do indivíduo determina a possibilidade de que o cromossomo possa fazer parte das gerações seguintes. O procedimento básico de um Algoritmo Genético [16] é resumido na figura 2.1.

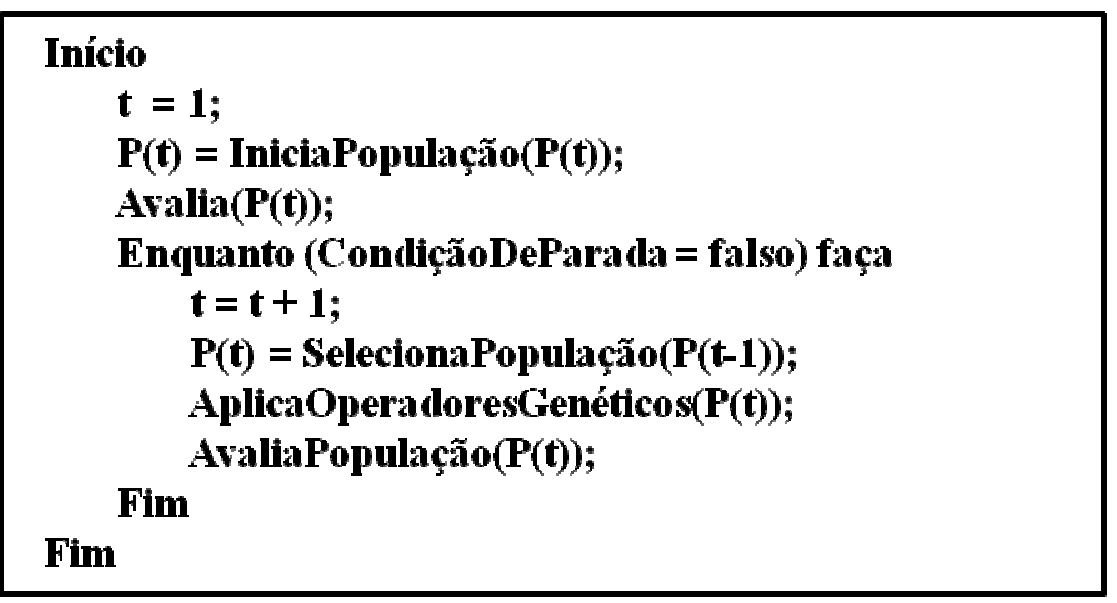

Figura 2.1. Estrutura básica de um Algoritmo Genético.

Para determinar o final da evolução, pode-se fixar o número de gerações, o número de indivíduos avaliados, ou ainda condicionar o algoritmo à obtenção de uma solução satisfatória, isto é, quando se atingir um ponto ótimo predefinido. Outras condições para a parada incluem o tempo de processamento e o grau de similaridade entre os elementos numa população (convergência por falta de diversidade entre os indivíduos). As seções seguintes apresentam em mais detalhe cada um dos componentes de um Algoritmo Genético.

\subsection{1}

\section{Representação}

A solução de um problema pode ser representada por um conjunto de parâmetros (genes), unidos para formar uma cadeia de valores (cromossomos); este processo chama-se codificação. As soluções (cromossomos) são codificadas através de uma sequência formada por caracteres de um sistema alfabético. Originalmente, utilizou-se o alfabeto binário $(0,1)$, porém, novos modelos de AGs codificam as soluções com 
outros alfabetos, como, por exemplo, números reais [17]. Assim, a representação é um aspecto fundamental na modelagem de um AG para a solução de um problema. Ela define a estrutura do cromossomo, com os respectivos genes que o compõem, de maneira que este seja capaz de descrever todo o espaço de busca relevante do problema. A decodificação do cromossomo consiste basicamente na construção da solução real do problema a partir do cromossomo, isto é, o processo de decodificação constrói a solução para que esta seja avaliada pelo problema.

\subsection{2}

\section{Avaliação}

A avaliação é a ligação entre o AG e o problema a ser solucionado. Ela é feita através de uma função que melhor representa o problema e tem por objetivo oferecer uma medida de aptidão de cada indivíduo na população corrente, que irá dirigir o processo de busca. Dado um cromossomo, a função de avaliação consiste em associar-se um valor numérico, o qual supõe-se proporcional à "utilidade" ou à "habilidade"do indivíduo representado em solucionar o problema em questão.

\subsection{3}

\section{Operadores genéticos}

Operadores genéticos são algoritmos que modificam ou replicam genes de indivíduos de uma geração para outra, possibilitando evoluir a solução. Os mais conhecidos são os de reprodução, crossover (cruzamento) e mutação.

A reprodução é um componente essencial de um Algoritmo Genético. Este operador, baseado no valor da aptidão dos indivíduos, seleciona aqueles que farão parte da próxima geração. Com isto os cromossomos mais aptos (valor de aptidão maior) têm maior probabilidade de contribuir para a formação de um ou mais indivíduos da população seguinte. Existem basicamente os seguintes métodos: troca de 
toda a população; troca de toda população com elitismo, onde todos os cromossomos são substituídos, sendo o cromossomo mais apto da população corrente copiado para a população seguinte e troca parcial da população (steady state), onde os $\mathrm{M}$ melhores indivíduos da população corrente são copiados para a população seguinte [13; 14; 17].

Os operadores de mutação são responsáveis pela divergência das soluções, explorando o espaço de busca; enquanto os operadores de cruzamento fazem com que as soluções se combinem, tirando proveito de determinado subespaço de busca. Esses operadores variam de acordo com a representação utilizada. Neste trabalho, as simulações com AG utilizam a representação real e os operadores relacionados serão descritos a seguir. Outros operadores podem ser encontrados na literatura [17].

O operador real mais usual é o cruzamento aritmético. Este consiste de uma combinação linear entre dois genes, conforme mostrado na equação 2-1.

$$
v_{f}=f\left(v_{p 1}, v_{p 2}\right)=\alpha \cdot v_{p 1}+(1-\alpha) \cdot v_{p 2}
$$

onde $\alpha \in[0,1]$ é uma variável aleatória e $v_{f}$ é o valor do gene filho, gerado em função dos valores dos genes dos pais $v_{p 1}$ e $v_{p 2}$.

Entre as mutações, os dois tipos mais comuns são a mutação uniforme e a não uniforme. A uniforme explora todo o espaço de busca igualmente, equação 2-2, sendo independente dos pais.

$$
v_{f}=\alpha \cdot\left(v_{\max }-v_{\min }\right)+v_{\min }
$$

onde $v_{\max }$ e $v_{\min }$ são, respectivamente, os valores máximo e mínimo que tal gene pode assumir, ou seja, as restrições de limite desse gene.

Já a mutação não uniforme, faz com que os genes sorteados no espaço se concentrem em torno do gene pai, em função do número de gerações decorrido e de um bit aleatório. 


$$
\begin{gathered}
v_{f}=f\left(v_{p 1}\right)= \begin{cases}v_{p 1}+\Delta\left(t, v_{\max }-v_{\mathrm{p} 1}\right) & \text { se o bit for } 0 \\
v_{p 1}-\Delta\left(t, v_{\mathrm{p} 1}-v_{\min }\right) & \text { se o bit for } 1\end{cases} \\
\Delta(t, y)=y \cdot\left(1-\alpha^{\left(1-\frac{t}{T}\right)^{b}}\right)
\end{gathered}
$$

onde $t$ é a geração atual e $T$ o número máximo de iterações do algoritmo. Por fim, $b$ é um parâmetro que determina o grau de dependência de acordo com o número da geração.

\subsection{4}

\section{Parâmetros da evolução}

Os parâmetros que mais influenciam o desempenho do AG são:

Tamanho da população: o tamanho da população afeta o desempenho global e a eficiência dos AGs. Uma população muito pequena oferece uma pequena cobertura do espaço de busca, causando uma queda no desempenho. Uma população suficientemente grande fornece uma melhor cobertura do domínio do problema e previne a convergência prematura para soluções locais. Entretanto, com uma grande população tornam-se necessários mais recursos computacionais, ou um tempo maior de processamento do problema. Logo, deve-se buscar um ponto de equilíbrio no que diz respeito ao tamanho escolhido para a população.

Taxa de cruzamento: é a probabilidade de um indivíduo ser recombinado com outro. Quanto maior for essa taxa, mais rapidamente novas estruturas serão introduzidas na população. Entretanto, isso pode

gerar um efeito indesejável, pois a maior parte da população será substituída, ocorrendo, assim, perda da variedade genética, podendo ocorrer perda de estruturas de alta aptidão e convergência a uma população com indivíduos extremamente parecidos, indivíduos estes de solução boa ou não. Com um valor baixo, o algoritmo pode tornar-se muito lento para oferecer uma resposta aceitável. 
Taxa de mutação: é a probabilidade do conteúdo de um gene do cromossomo ser alterado aleatoriamente. A taxa de mutação previne que uma dada população fique estagnada em um valor, além de possibilitar que se chegue a qualquer ponto do espaço de busca. Porém, deve-se evitar uma taxa de mutação muito alta, uma vez que pode tornar a busca essencialmente aleatória, prejudicando fortemente a convergência para uma solução ótima.

GAP: controla a porcentagem da população que será substituída durante a próxima geração (substituição total, substituição com elitismo, substituição dos piores indivíduos da população atual, substituição parcial da população sem duplicatas).

Número de gerações: representa o número total de ciclos de evolução do AG, sendo este um de seus critérios de parada. Um número de gerações muito pequeno causa uma queda no desempenho, pois pode-se terminar a evolução antes de se ter alcançado a convergência para a solução de um problema. Para um valor grande faz-se necessário um maior tempo de processamento.

\section{3}

\section{Programação Genética}

A Programação Genética (PG) [13; 18 - 20] é uma técnica da CE que cria soluções (equações matemáticas ou programas de computador) para problemas, automaticamente. Esta técnica tem sido utilizada em diversas áreas como a Biotecnologia, Engenharia Elétrica, Análises Financeiras, Processamento de Imagem e Mineração de Dados [21].

Dentro de um espaço grande e restrito de programas de computador, a PG realiza uma busca pelos melhores indivíduos (programas) que resolvem um determinado problema. Esta busca é feita de forma a sintetizar e selecionar os programas envolvidos, através de operadores genéticos e populacionais [13].

Cada indivíduo pode ser denotado por uma expressão matemática composta por funções e terminais, codificados através de uma estrutura de árvore (figura 2.2). 


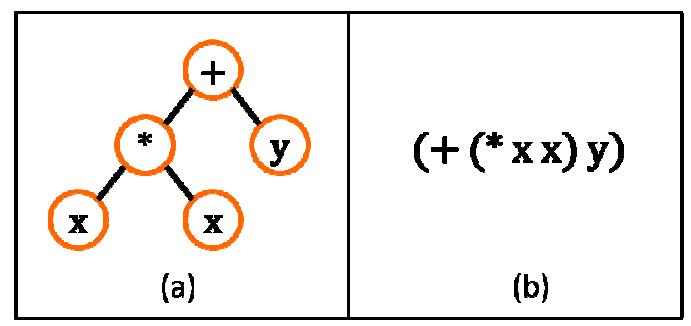

Figura 2.2. Representação do programa " $x^{2}+y$ ": (a) Representação sob a forma de árvore; (b) forma pré-fixada.

As funções aparecem nos vértices internos da árvore e podem ser desde operações aritméticas (como "soma", "subtração", "multiplicação" e "divisão"), funções matemáticas (como "seno", "cosseno" e "tangente"), operações booleanas (como "and", "or" e "not"), operadores condicionais (como "if" e "else") e funções de iteração (como "for" e "while"), até funções de recursão ou específicas do domínio do problema. Já os terminais são representados por variáveis de entradas e constantes (números reais ou binários, de acordo com o problema) e aparecem nos vértices extremos da árvore (folhas).

A síntese dos programas ocorre a partir dos conjuntos de terminais e de funções. Para que os programas criados pela PG sejam válidos, é necessário que os conjuntos de funções e de terminais atendam à propriedade de fechamento. Esta propriedade determina que cada função deve aceitar, como seus argumentos, qualquer valor que possa ser retornado por qualquer função ou terminal, garantindo que qualquer árvore gerada possa ser avaliada corretamente.

Para a aplicação da PG a um determinado problema deve-se:

- determinar os conjuntos de terminais e funções primitivas que serão utilizadas;

- definir uma medida de aptidão;

- estabelecer parâmetros para controlar a execução;

- definir um método para determinar o resultado;

- definir um critério para terminar a execução. 
A aptidão é medida a partir de uma função de avaliação que verifica o quão bem um programa executa sua tarefa em um dado problema. Em um caso de aproximação de função, ou previsão, a avaliação é o erro resultante da diferença entre a saída gerada pela PG e um alvo, sendo que, quanto mais próximo de zero, melhor é o programa.

$O$ processo de evolução da $P G$ se assemelha ao processo de evolução dos AGs, apresentado na seção 2.2. Os indivíduos da população inicial aleatória, agora formada por programas de computador, têm seus tamanhos (altura da árvore) limitados por um parâmetro. Cada indivíduo da população inicial é avaliado, e os de maior aptidão são selecionados por alguma heurística (método da roleta, torneio etc. [22]) para a aplicação dos operadores genéticos. Após a aplicação dos operadores genéticos, os programas resultantes passam pelo critério de parada, que pode ser um número máximo de gerações ou a chegada a um ponto satisfatório do problema. Caso o critério de parada não seja atendido, os programas passam para a população da nova geração e as etapas são repetidas.

Os operadores genéticos utilizados na PG são diferentes dos utilizados nos AGs, devido à diferença na representação de seus indivíduos. Os operadores são [13]:

- Reprodução Direta: o indivíduo da população é selecionado de acordo com algum método baseado na aptidão e é copiado, sem qualquer alteração, para a próxima geração;

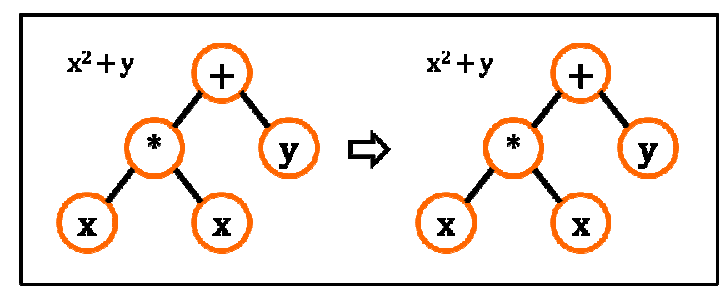

Figura 2.3. Operador genético de Reprodução para PG. O indivíduo é copiado para a próxima geração.

- Cruzamento (crossover): dois indivíduos são selecionados, e um ponto de corte é escolhido aleatoriamente em cada um dos 
genitores. As subárvores resultantes são permutadas, formando novos programas para a próxima geração;

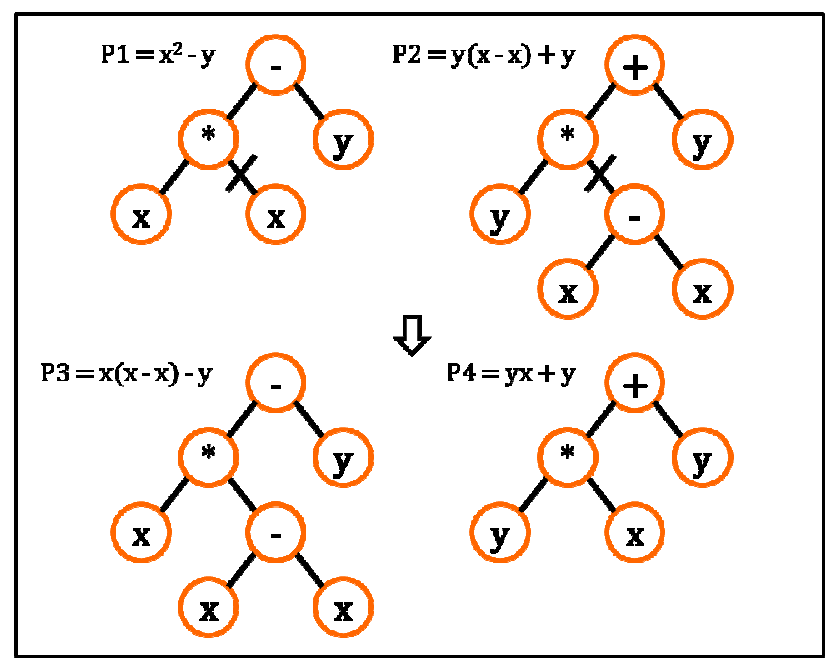

Figura 2.4. Operador genético de Cruzamento para PG. O cruzamento entre os indivíduos P1 e P2 geram os indivíduos P3 e P4.

- Mutação: seleciona aleatoriamente uma aresta qualquer da estrutura em árvore. Em seguida, esta operação remove a subárvore que está neste ponto e insere uma nova subárvore, gerada aleatoriamente.

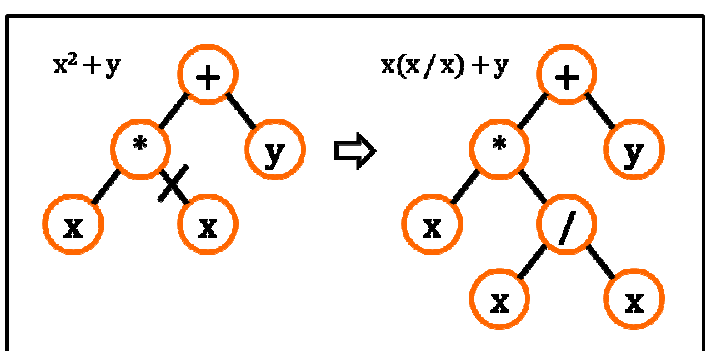

Figura 2.5. Operador genético de Mutação para PG. Uma subárvore aleatória substitui a subárvore que está abaixo de um ponto selecionado.

- Permutação: escolhe-se um ponto interno de um programa e os ramos são permutados. A permutação a ser realizada é escolhida aleatoriamente (para 3 ramos existem 3! possibilidades de permutação). Se o programa for uma função comutativa, a permutação não tem efeito; 


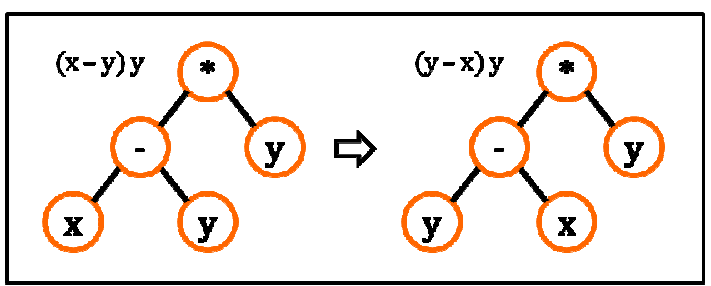

Figura 2.6. Operador genético de Permutação para PG. Os elementos x e y, da subtração, foram permutados pelo operador genético.

- Edição: proporciona um meio para editar e simplificar expressões (por exemplo, no domínio booleano, um programa "(and $x \mathrm{x})$ " é substituído por "x", "(not(not(x))" é substituído por "x"). A edição pode ser utilizada de duas formas, externa à execução, obtendo uma saída mais legível, e durante a execução, produzindo uma saída simplificada. Este operador genético consome muito tempo e sua frequência de aplicação pode ser controlada através de um parâmetro;

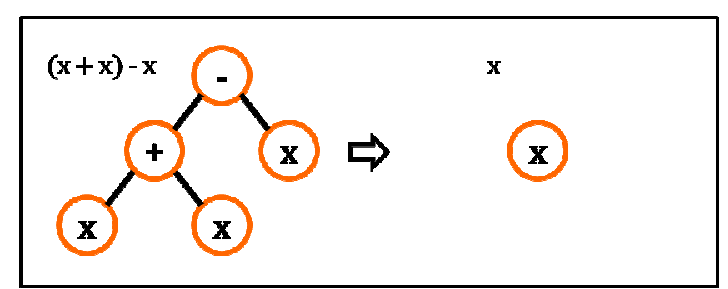

Figura 2.7. Operador genético de Edição para PG. O programa foi simplificado pelo operador genético.

- Encapsulamento: seleciona aleatoriamente subárvores e atribui a elas um nome para que sejam referenciadas e utilizadas posteriormente. Para esta atribuição, seleciona-se um ponto interno aleatório de um indivíduo, remove-se a subárvore no ponto selecionado e uma nova função é definida para referenciar esta subárvore. A esta nova função é atribuído um nome, e o conjunto de funções é acrescido desta nova função. Uma chamada da função encapsulada é criada para o ponto selecionado do indivíduo. A função encapsulada é fator potencial para interromper o efeito de cruzamento, pois a função torna-se um ponto indivisível; 


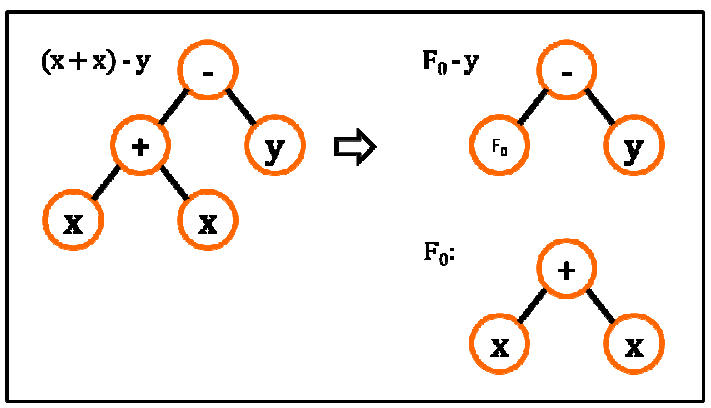

Figura 2.8. Operador genético de Encapsulamento para PG. A função " $F_{0}=(x+x)$ " foi encapsulada pelo operador genético.

- Destruição (decimation): é uma forma de reduzir o número de indivíduos com baixa aptidão nas primeiras gerações. É controlado por dois parâmetros: a porcentagem de indivíduos mantidos e a condição que especifica quando este operador será chamado. Indivíduos são selecionados para permanecer, com base na aptidão. Por exemplo, se a porcentagem for igual a 10\%, e a geração 0 for a condição que especifica quando este operador será chamado, somente $10 \%$ da população permanecerá na geração 0 .

Os parâmetros de controle estão descritos na tabela 2.1.

\begin{tabular}{cc}
\hline \hline \multicolumn{1}{c}{ Parâmetros de controle } \\
\hline tamanho da população & frequência de edição \\
taxa de reprodução & condição de chamada de \\
taxa de mutação & destruição \\
taxa de cruzamento & taxa de destruição \\
taxa de distribuição dos pontos & método de geração da \\
de cruzamento & população inicial \\
altura da árvore & método de seleção do pai \\
(primeiro e segundo) & de ajustes de medida de \\
taxa de permutação & aptidão \\
\hline
\end{tabular}

Tabela 2.1. Parâmetros de controle de um algoritmo de PG. 


\section{4}

\section{Programação Genética Multigênica}

A PG cria um programa de computador automaticamente, como visto na seção 2.3. Este programa de computador pode ser uma equação matemática que prediz uma variável de saída $Y_{i}$ (sendo $i$, o número de elementos) a partir de uma variável de entrada $X_{i j}$ (sendo $i$ o número da linha e $j$ o número da coluna do elemento). A Programação Genética Multigênica (PGMG) [23; 24] pode ser encarada como uma generalização da $P G$ tradicional, pois denota um indivíduo como um complexo de estrutura em árvores, também chamados de genes, que da mesma forma que a PG recebe uma variável de entrada $X_{i j}$, buscando predizer uma variável de saída $Y_{i}$ (figura 2.9).

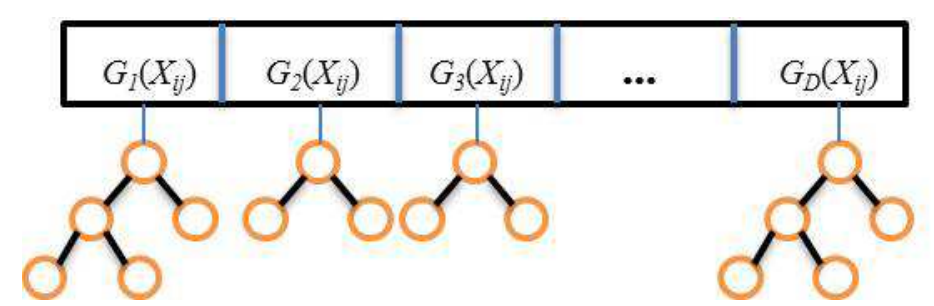

Figura 2.9. Exemplo de um indivíduo multigênico [25].

Cada árvore desta estrutura é uma solução parcial para o problema, sendo que a saída final pode ser resultado da combinação linear, dada por:

$$
\widehat{Y}_{l}=\beta_{0}+\sum_{\mathrm{d}=1}^{\mathrm{D}} \beta_{d} G_{d}
$$

$\widehat{Y}_{i}$ é a saída resultante de um indivíduo qualquer da população, $\beta_{0}$ é o coeficiente linear (ou intercepto), $\beta_{d}$ são parâmetros lineares e $\left(G_{d}\right.$, onde $d=1,2,3, \ldots, D$; e $D$ é o número de árvores) são as saídas de cada equação decodificada no indivíduo. Os $\beta_{d}$ desse método podem ser estimados por mínimos quadrados, levando-se em conta que o cálculo do erro $\varepsilon_{i}=Y_{i}-\widehat{Y}_{i}$ é factível. A partir desta métrica de erro, é possível 
avaliar a qualidade global do indivíduo. É fácil ver que quando $D=1$, a PGMG reduz-se à solução obtida por uma PG clássica.

Em relação aos operadores genéticos, a operação de mutação na PGMG é similar à efetuada na PG clássica. No caso da operação de cruzamento, é necessária uma distinção do nível em que a operação é realizada, sendo possível aplicar o cruzamento no baixo e no alto nível [25]. A figura 2.10 apresenta um indivíduo multigênico com cinco equações $(D=5)$ efetuando uma operação de cruzamento de baixo nível, enquanto a figura 2.11 apresenta a operação de mutação.

O baixo nível é o espaço onde é possível manipular as estruturas (terminais e funções) das equações presentes em um indivíduo. No caso, tanto a mutação quanto o cruzamento de baixo nível na PGMG são semelhantes ao modo efetuado na PG clássica.

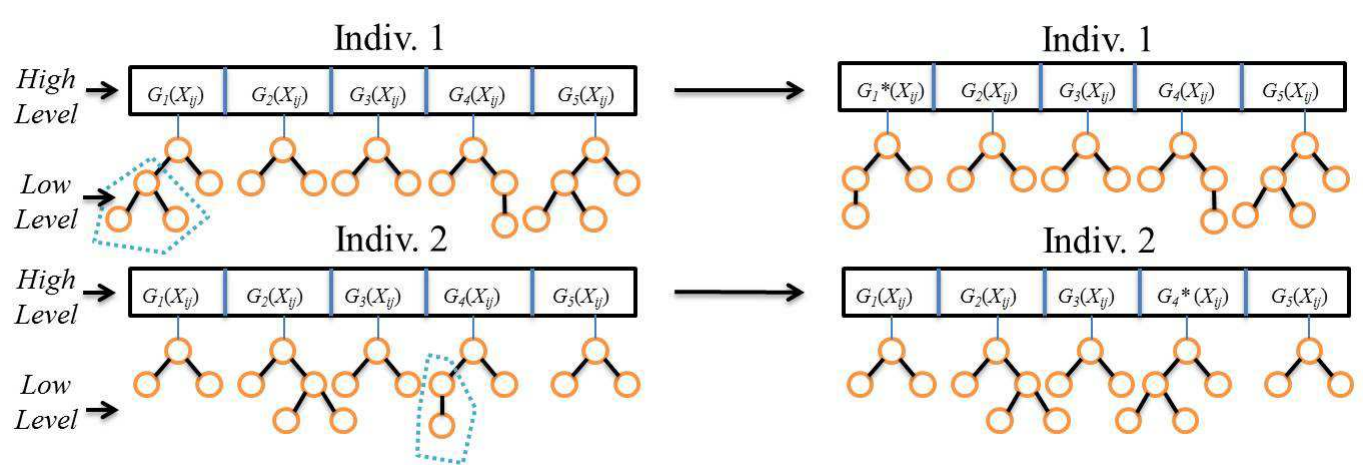

Figura 2.10. Operação de cruzamento de baixo nível em um indivíduo multigênico [25].
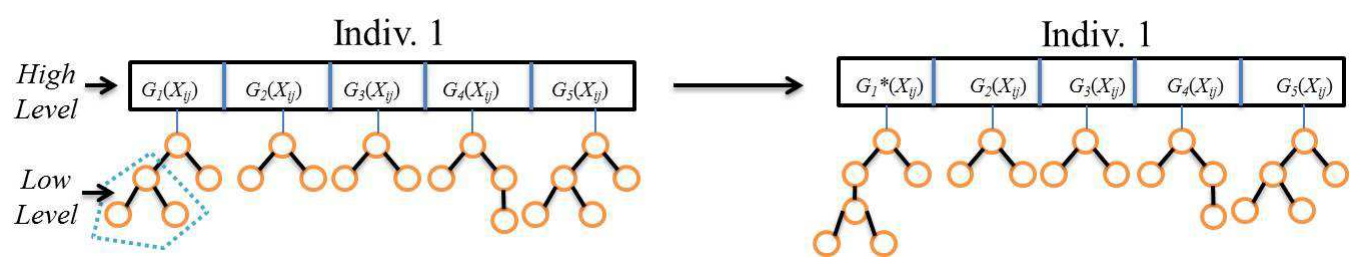

Figura 2.11. Operação de mutação em um indivíduo multigênico [25].

Um exemplo de cruzamento de alto nível para um indivíduo com cinco equações é apresentado na figura 2.12. O alto nível é o espaço em que se manipulam de forma macro as equações presentes no indivíduo. Logo, verifica-se que a partir de dois pontos aleatórios é permutado um número de equações, neste caso três, de um indivíduo para o outro. Este 
ponto de corte aleatório pode ser simétrico, ou seja, trocando o mesmo número de equações entre indivíduos, ou assimétrico caso contrário. Os efeitos do cruzamento de alto nível tendem a afetar mais substancialmente a saída resultante, do que a operação de cruzamento de baixo nível e a mutação.

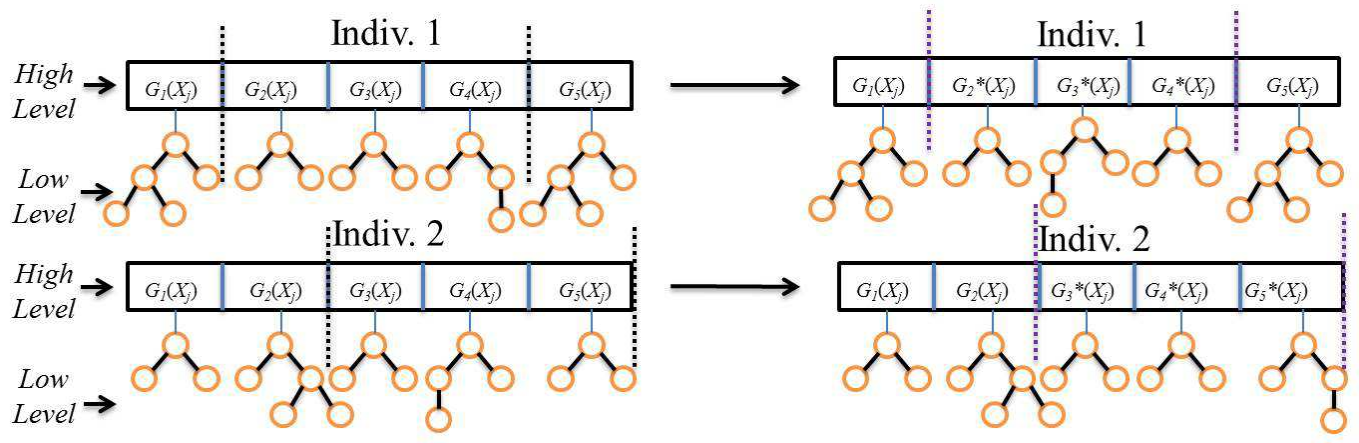

Figura 2.12. Operação de cruzamento de alto nível em um indivíduo multigênico [25].

\section{5}

\section{Otimização por Programação Genética}

Em 2008, Pujol e Poli apresentaram o algoritmo Parameter Mapping Approach (PMA) [20], que consiste basicamente em, dado um vetor $X_{i}^{*}$ de parâmetros ótimos que minimizam a função objetivo, encontrar, a partir de parâmetros $X_{i}$ arbitrários (default), uma função pma $\left(X_{i}\right)$, tal que $X_{i}^{*} \approx p m a\left(X_{i}\right)$. A figura 2.13 ilustra um exemplo desse processo.

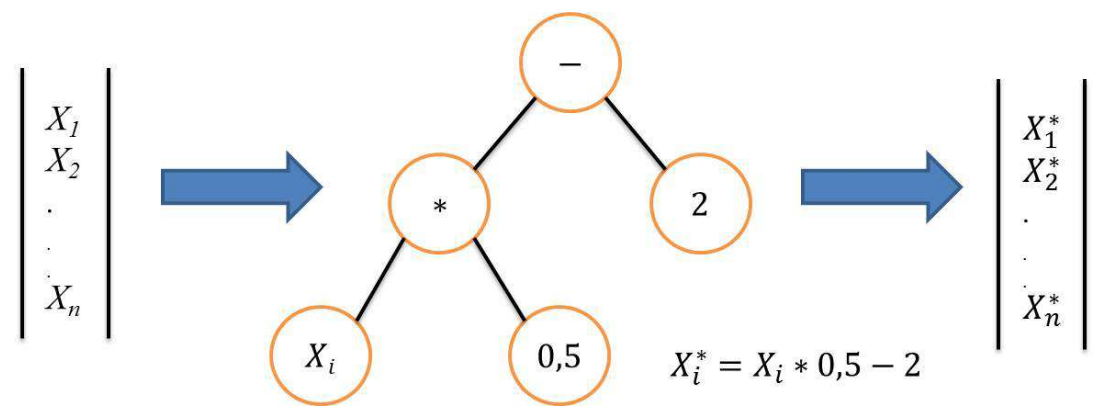

Figura 2.13. Exemplificação do algoritmo PMA [25].

Portanto, a PG é utilizada para sintetizar essa função, a partir do uso de operadores de recombinação e mutação. É fácil notar que o 
método funciona relativamente bem em problemas cujas soluções são triviais, como exibido em [20]. Por exemplo, considere $X_{i}^{*}=0$, para todo $i$ como o vetor de soluções ótimas para uma função. Então, basta a PG encontrar uma função $p m a\left(X_{i}\right)=X_{i}-X_{i}$, que o problema de otimização é concluído com otimalidade.

Entretanto, quando o conjunto de soluções ótimas não é trivial, o PMA tende a enfrentar maiores dificuldades. A figura 2.14a e 2.14b dispõem, graficamente, soluções ótimas quando $X_{i}^{*}=1$ e $X_{i}=1+r_{i}$ (onde $r_{i}$ é um valor de uma distribuição uniforme, com valores entre -1 a 1), respectivamente.
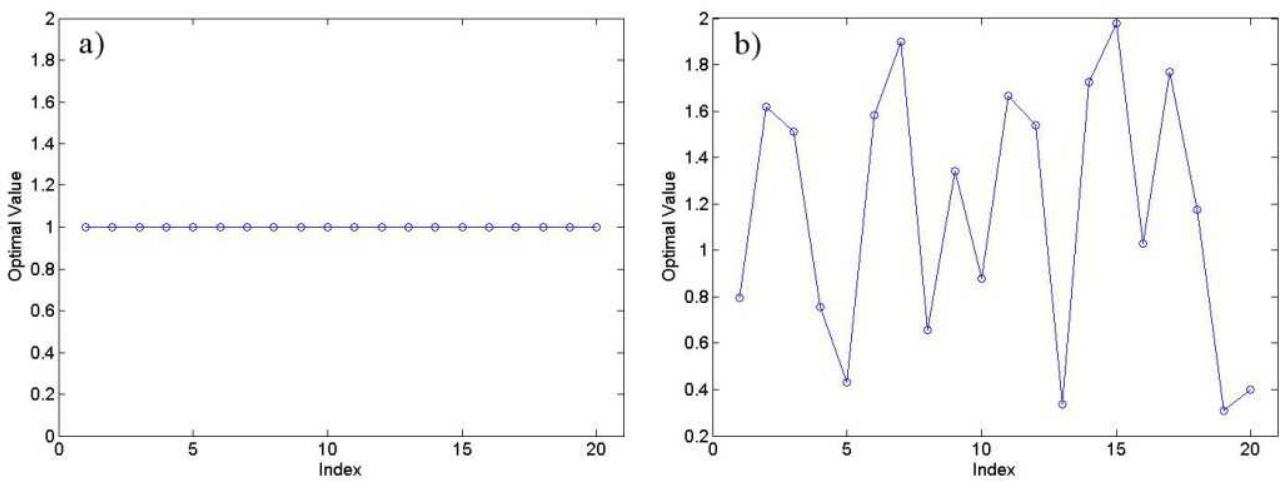

Figura 2.14. Solução trivial (a) e não trivial (b) [26].

Logo, buscar um $p m a\left(X_{i}\right)$ tal que demonstre um comportamento semelhante ao da figura 2.14b é notoriamente mais complexo do que o da figura 2.14a. Este caso é relatado em [20], que apresenta uma maior incidência de resultados inferiores.

Em [26], uma solução foi proposta, onde estabelece-se um conjunto de funções responsáveis em buscar determinados parâmetros, ao invés de uma única ser incumbida por todos. Esta solução é denominada de Otimização por Programação Genética (OPG).

De forma ampla, o método OPG consiste em sintetizar uma quantidade $k$ de funções a partir da PGMG. Para exemplificar a distinção entre PMA e OPG, considere-se a figura 2.15 que demonstra os parâmetros ótimos (pontos no gráfico) de um problema de otimização hipotético. A figura 2.15a apresenta a função que deve ser encontrada pelo PMA para solucionar o problema hipotético de otimização, enquanto 
que a figura 2.15b exibe, para o mesmo problema, a solução encontrada pelo OPG. Neste caso, $k=3$, logo o método OPG particiona, em três, o número de parâmetros que são buscados, dispondo para cada função a responsabilidade de otimizar uma terça parte do problema. No limite, quando $k=n$, sendo $n$ o número de parâmetros a serem otimizados, o método OPG elabora para cada parâmetro uma função que recebe um valor arbitrário e retorna este transformado pela função decodificada no indivíduo.
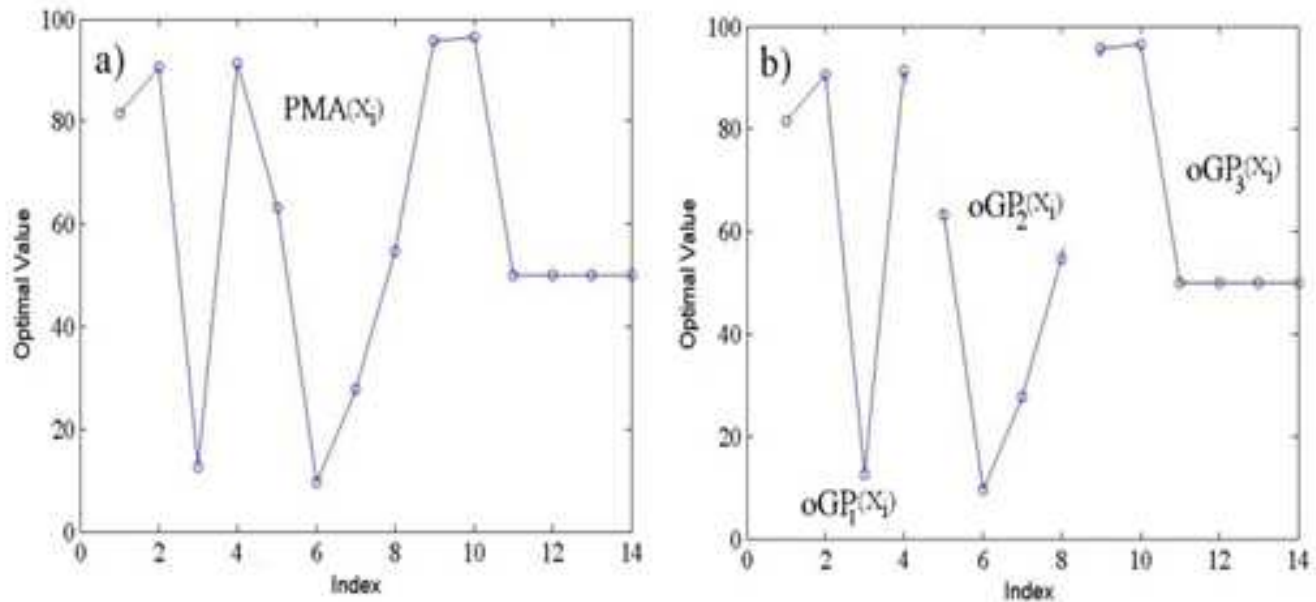

Figura 2.15. Exemplo da distinção entre as soluções encontradas por PMA e OPG [26].

Da mesma forma, quando $k=1$, o OPG se resume ao PMA. Cabe ressaltar que no caso limite $(k=n)$, não é necessário incluir variáveis de entrada (o vetor $X_{i}$, como no exemplo) como terminal de entrada da OPG, bastando somente incluir as constantes. Como cada função retorna somente um valor para um dos parâmetros da função objetivo, este pode ser representado por um número que é resultado de combinações aritméticas de constantes de entrada.

De forma geral, o pseudo-código [26] do método OPG, para uma função objetivo qualquer, é descrito na figura 2.16. 


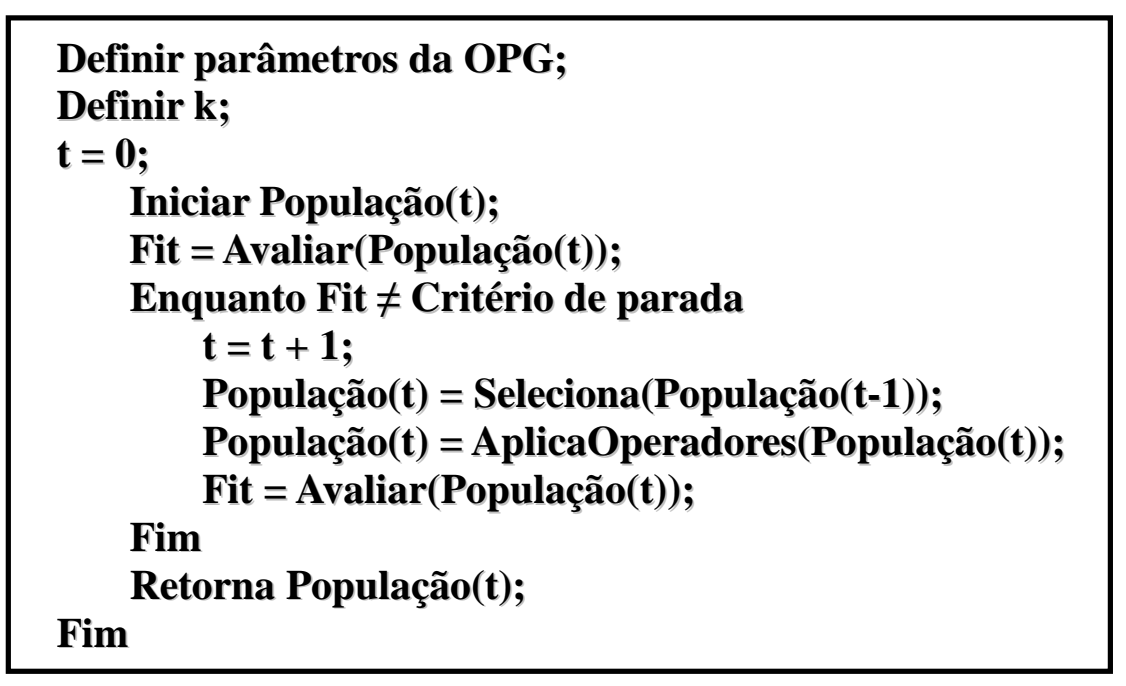

Figura 2.16. Pseudo-código do método OPG.

Então, o algoritmo de otimização OPG tem início a partir da especificação dos parâmetros populacionais (tamanho da população, número de gerações etc.) e dos operadores genéticos (taxa de cruzamento, mutação etc.), que são comumente definidos em uma execução de Programação Genética, ou de Programação Genética Multigênica. Na sequência, é estabelecido pelo usuário o valor de $k$, que é o número de funções incorporadas em um indivíduo.

A partir dessas especificações, uma população de indivíduos com $k$ funções é gerada aleatoriamente. As soluções expressas por cada indivíduo são avaliadas na função objetivo do problema de otimização explorado. Após toda a população ter sido avaliada, verifica-se se 0 critério de parada foi atendido; se sim, retorna a população atual; caso contrário, o algoritmo entra em um loop que só é interrompido caso o critério de parada seja alcançado.

Durante o loop, são efetuadas três operações: seleção, aplicação de operadores e avaliação. A primeira consiste em escolher, a partir de algum método heurístico (roleta, torneio etc.) [20], os entes da próxima população. Então, nesta nova população, são aplicados operadores de cruzamento de baixo e alto nível e a mutação.

Esta nova população é reavaliada, e novamente é testado se o critério de parada do algoritmo foi alcançado; se for atendido, a população 
atual é retornada; caso contrário, este processo é retomado quantas vezes for necessário.

Em [26], o método OPG foi submetido aos mesmos testes realizados pelo PMA, em 2008, por Pujol e Poli [20], obtendo resultados melhores, para a maioria dos casos benchmark, do que o PMA. 


\section{3}

\section{Aglomerados atômicos e moleculares}

\section{1 \\ Introdução}

Aglomerados, também chamados de agregados, podem ser compostos por algumas unidades ou milhões de átomos ou moléculas [1]. Os aglomerados possuem propriedades diferentes quando comparados às moléculas isoladas ou grandes pedaços de matéria. Por exemplo, alguns metais (e.g. paládio) não são magnéticos no estado sólido, mas apresentam magnetismo quando formam agregados. Outra razão importante para este tipo de estudo é o entendimento da evolução das propriedades com o aumento gradual do tamanho dos aglomerados [1].

A teoria e a modelagem computacional tem um papel muito importante no estudo dos aglomerados, já que muitas das suas propriedades são difíceis de serem medidas experimentalmente e dados de espectroscopia são geralmente interpretados em termos de modelos teóricos.

\section{2}

\section{Otimização estrutural de aglomerados}

Quando um cálculo empírico, semiempírico ou ab initio é usado para descrever as interações de um aglomerado, um dos primeiros objetivos é encontrar o arranjo de átomos (ou íons, ou moléculas) que corresponde à menor energia, ou seja, o mínimo global na superfície de energia potencial [27]. A importância de encontrar o aglomerado que corresponde ao mínimo global se dá por este ser o candidato mais provável de ser formado, já que é o mais estável. Porém, dependendo das condições experimentais (temperatura, pressão, fluxos etc.), estruturas de metaestáveis podem ser formadas, sendo importante 
estudar não somente o aglomerado de menor energia, mas também aqueles de energia próxima.

\section{3}

\section{Otimização estrutural de aglomerados de carbono}

Um exemplo de otimização estrutural de aglomerados pode ser visto em [9] e [10], onde Doye e Wales analisaram a geometria de aglomerados de carbono. Aglomerados de carbono de diferentes tamanhos foram submetidos a um processo de otimização de geometria envolvendo várias etapas de um algoritmo estocástico em conjunto com simulações de dinâmica molecular utilizando um potencial de Morse para o cálculo da energia potencial. Esse processo de otimização teve como objetivo encontrar a geometria de menor energia, mínimo global, para cada tamanho de aglomerado.

O potencial de Morse foi escolhido, por Doye e Wales, devido à sua simplicidade, pois é possível realizar mudanças drásticas e sistemáticas na superfície de energia potencial de um aglomerado, alterando-se apenas o valor de um parâmetro. Este parâmetro determina o alcance do potencial para um par de átomos e sua equação pode ser escrita como:

$$
\begin{aligned}
& V_{M}=\epsilon \sum_{i<j} e^{\beta\left(r_{0}-r_{i j}\right)}\left(e^{\beta\left(r_{0}-r_{i j}\right)}-2\right) \\
& V_{M} \equiv \sum_{i<j} e^{\rho_{0}\left(1-r_{i j}^{\prime}\right)}\left(e^{\rho_{0}\left(1-r_{i j}^{\prime}\right)}-2\right)
\end{aligned}
$$

onde $\epsilon=1$ e $r_{0}=1$ definem as unidades reduzidas de energia $\mathrm{e}$ comprimento, respectivamente; $\rho_{0}=\beta r_{0}$, e $r_{i j}^{\prime}$ representa a distância entre os átomos $i$ e $j$ nestas unidades reduzidas.

A unidade reduzida expressa grandezas moleculares e atômicas por números da ordem de potências de dez, com expoentes relativamente pequenos, o que reduz o número de erros de arredondamento computacional, devido ao limite da memória dos computadores, e facilita a 
interpretação das grandezas expressas, evitando números muito pequenos ou grandes.

O parâmetro $\rho_{0}$ determina o alcance da parte atrativa do potencial de Morse. Como pode ser visto na figura 3.1, valores baixos de $\rho_{0}$ resultam em um potencial mais suave e de maior alcance, e valores mais altos resultam em um potencial de maior inclinação e menor alcance. $O$ parâmetro $\rho_{0}$ afeta mais drasticamente a inclinação do potencial para menores distâncias interatômicas.

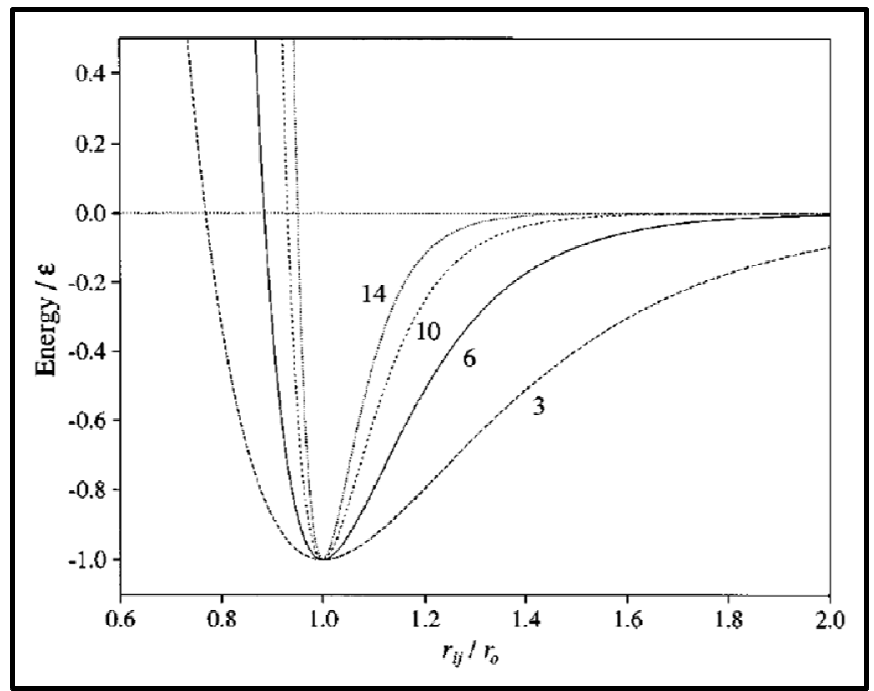

Figura 3.1. Curvas do potencial de Morse para diferentes valores de $\rho_{0}$. Cada curva possui uma legenda referente ao seu valor de $\rho_{0}$. A figura foi reproduzida da Ref. [9].

Para avaliar a geometria dos aglomerados de carbono, Doye e Wales realizaram otimizações considerando vários valores de $\rho_{0}$ conforme as curvas apresentadas na figura 3.2, ou seja, assumindo os valores iguais a: 3, 6, 10 e 14. A tabela 3.1 apresenta a energia mínima global, encontrada em [9] e [10], para cada aglomerado de carbono de 5 a 25 átomos, alterando o valor $\rho_{0}$. 


\begin{tabular}{ccccc}
\hline \hline $\begin{array}{c}\text { Número de } \\
\text { átomos }\end{array}$ & $\rho_{0}=3$ & $\rho_{0}=6$ & $\rho_{0}=10$ & $\rho_{0}=14$ \\
\hline 5 & $-9,299500$ & $-9,044930$ & $-9,003565$ & $-9,000283$ \\
6 & $-13,544229$ & $-12,487810$ & $-12,094943$ & $-12,018170$ \\
7 & $-17,552961$ & $-16,207580$ & $-15,956512$ & $-15,883113$ \\
8 & $-22,042901$ & $-19,327420$ & $-18,964638$ & $-18,883688$ \\
9 & $-26,778449$ & $-23,417190$ & $-22,850758$ & $-22,644892$ \\
10 & $-31,888630$ & $-27,473283$ & $-26,583857$ & $-26,132735$ \\
11 & $-37,930817$ & $-31,521880$ & $-30,265230$ & $-29,596054$ \\
12 & $-44,097880$ & $-36,400278$ & $-34,366755$ & $-33,332305$ \\
13 & $-51,737046$ & $-42,439863$ & $-39,662975$ & $-37,258877$ \\
14 & $-56,754744$ & $-45,619277$ & $-42,675222$ & $-40,798348$ \\
15 & $-63,162119$ & $-49,748409$ & $-46,541404$ & $-44,806437$ \\
16 & $-69,140648$ & $-53,845835$ & $-50,261947$ & $-48,814517$ \\
17 & $-75,662417$ & $-57,941386$ & $-53,983559$ & $-52,822588$ \\
18 & $-82,579266$ & $-62,689245$ & $-57,657135$ & $-56,830907$ \\
19 & $-90,647461$ & $-68,492285$ & $-62,166843$ & $-60,812425$ \\
20 & $-97,417393$ & $-72,507782$ & $-65,679115$ & $-64,791953$ \\
21 & $-104,336946$ & $-76,529139$ & $-69,449904$ & $-68,783571$ \\
22 & $-112,041223$ & $-81,136735$ & $-73,494292$ & $-72,791747$ \\
23 & $-120,786879$ & $-86,735494$ & $-78,325380$ & $-77,302495$ \\
24 & $-127,884549$ & $-90,685398$ & $-82,370214$ & $-81,309508$ \\
25 & $-136,072704$ & $-95,127899$ & $-86,989688$ & $-85,477376$ \\
\hline
\end{tabular}

Tabela 3.1. Energia mínima global encontrada nas Refs. [9] e [10] para os vários valores de $\rho_{0}$ considerados $(3,6,10$ e 14). As energias estão em $\epsilon$.

\section{4}

\section{Otimização estrutural de aglomerados por Algoritmos Genéticos}

Como estruturas metaestáveis de baixa energia podem ser formadas, e o número de mínimos aumenta exponencialmente com o aumento do tamanho do aglomerado, encontrar o mínimo global é uma tarefa que envolve um alto custo computacional. Já foi provado que métodos como simulação Monte Carlo, Dinâmica Molecular e Simulated Anneling possuem dificuldades para encontrar o mínimo global com alguns tipos de interações [1]. De forma alternativa, Algoritmos Genéticos (AG) têm sido utilizados na otimização de geometria de aglomerados atômicos e moleculares, permitindo encontrar o mínimo global e os mínimos locais relevantes a um custo computacional razoável $[1 ; 6 ; 27$ 29].

O uso de AG para a otimização da geometria de aglomerados teve início na década de 1990 por Hartke [7] e Xiao e Williams [8] para a otimização de pequenos aglomerados de silício e agregados moleculares, respectivamente. Em ambos os casos, a geometria dos aglomerados era codificada por bits. Depois de seu trabalho pioneiro, Hartke publicou o 
resultado da otimização da geometria por AG para outros aglomerados, tais como água [30] e mercúrio [31].

Uma evolução importante para a otimização dos aglomerados por AG foi introduzida por Zeiri, que passou a representar a estrutura do aglomerado através de números reais [32]. Essa metodologia permitiu representar a posição dos elementos de forma contínua, removendo a necessidade de codificação e decodificação do cromossomo binário. Em seguida, Deaven e Ho desenvolveram um algoritmo híbrido onde uma minimização local por gradiente é aplicada sempre que uma nova estrutura é gerada pelo AG [33]. A introdução da minimização local transforma a curva do potencial de energia em uma superfície de degraus, onde cada degrau corresponde a uma base de atração, como mostrado na figura 3.2. Essa simplificação facilita consideravelmente a busca pelo mínimo global, reduzindo o espaço de busca. Nesse contexto, a utilização da minimização local corresponde a uma evolução lamarquiana, ao invés da darwiniana, já que os indivíduos agregam aos seus cromossomos características que adquiriram pela minimização local, alterando parte do que foi herdado.

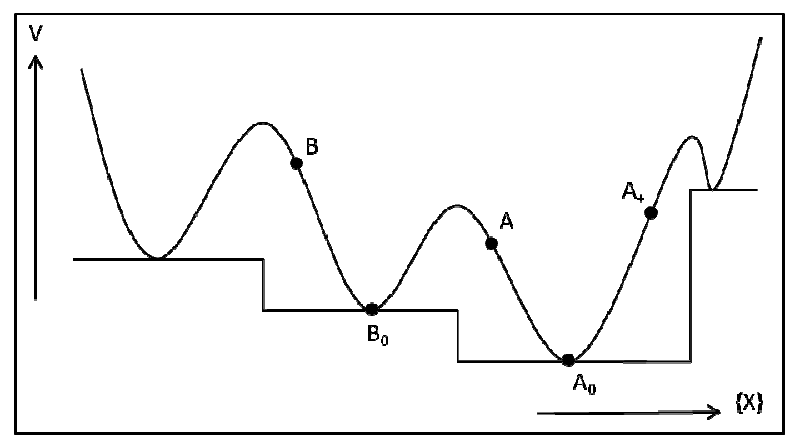

Figura 3.2. Simplificação da superfície de energia por degraus.

Outra melhoria introduzida por Deaven e Ho foi a adoção de um novo operador tridimensional, chamado de corte e união (em inglês, cut and splice) [33]. Este operador dá um significado físico maior ao processo de crossover. Neste caso, bons esquemas correspondem às regiões dos aglomerados pais que possuem energia local mais baixa. Deaven e Ho aplicaram este operador na otimização de aglomerados de carbono 
usando potenciais empíricos, permitindo encontrar muito mais mínimos de baixa energia que outros operadores [1].

Em 2009, Vilela Neto [5] propôs um novo operador genético para combinar aglomerados que possuam mais de um tipo de átomo. Este operador se baseia em uma variação do operador corte e união combinada com a metodologia de um operador para problemas baseados em ordem [17]. Este operador mais recente não gera indivíduos inválidos para aglomerados com mais de um tipo de átomo

Com os objetivos de evitar a estagnação e manter a diversidade da população, um ou mais operadores de mutação são introduzidos nos Algoritmos Genéticos. Johnston apresentou uma diversidade de operadores para aglomerados atômicos em [1], que foram estendidos aos aglomerados moleculares em [5].

Devido ao elevado número de avaliações, e como a função objetivo envolve o cálculo da energia, métodos aproximados (empíricos e semiempíricos) são mais utilizados devido ao baixo custo computacional. Mais recentemente, Alexandrova e Boldyrev apresentaram a otimização de diversos aglomerados usando métodos quânticos para o cálculo da energia, tais como o método da Teoria do Funcional da Densidade (DFT) $[28 ; 29]$. 


\section{Otimização estrutural de aglomerados de carbono por Programação Genética}

\section{1}

\section{Introdução}

O capítulo 2 mostra que o recente método de otimização OPG é superior, para a maioria dos casos benchmark, em relação ao PMA, conforme os testes de Koshiyama et al. em [26]. Analisando estes resultados e o histórico do uso de Algoritmos Genéticos na otimização de aglomerados, conforme o capítulo 3, inicia-se, neste trabalho, a abordagem de otimização estrutural de aglomerados por OPG.

Este trabalho visa a otimização estrutural de aglomerados de carbono de 5 a 25 átomos. Para validação do uso do método OPG, duas abordagens diferentes e independentes são realizadas. A primeira consiste na otimização por AG e a segunda por OPG, possibilitando, assim, a comparação entre os dois métodos. Nos dois casos, a energia potencial do sistema é calculada pelo potencial de Morse.

Outra análise é feita através da comparação dos resultados com o valor de menor energia de cada aglomerado, tendo em vista que estes valores são conhecidos e estão disponíveis em [10]. A geometria de cada aglomerado, também, é comparada com os aglomerados disponibilizados por Doye e Wales [10].

\section{2}

\section{Metodologia}

Todos os programas desenvolvidos neste trabalho foram feitos no MATLAB e utilizam precisão dupla em seus cálculos. Para as simulações, foi utilizado um computador Intel ${ }^{\circledR}$ Core $^{T M}$ i7, CPU X980 @3,33 GHz, 8,00Gb de memória RAM, barramento de 64 bits e sistema operacional Windows 7 Professional. 
Tanto para o $A G$ quanto para $\circ \mathrm{OPG}$, foram realizadas dez otimizações para cada aglomerado de carbono, de 5 a 25 átomos, assumindo quatro valores diferentes para o parâmetro $\rho_{0}(3,6,10$ e 14; tais valores foram escolhidos em razão dos valores assumidos em [9] e [10]). Foram realizadas, ao todo, 840 simulações com o AG e 840 simulações com o OPG, de modo a permitir uma comparação entre os dois métodos e os resultados apresentados em [10].

\subsection{1}

\section{Algoritmo Genético}

Por se tratar de um problema de otimização estrutural de um aglomerado atômico, foram utilizados três genes em números reais $(x, y \mathrm{e}$ $z$ ), para representar a posição de cada átomo. Logo o tamanho do cromossomo é igual a $3 N$, onde $N$ é o número total de átomos. Os valores para $x, y$ e $z$ foram limitados entre -1 e 1 , em razão dos valores assumidos em [9] e [10]. A figura 4.1 mostra um exemplo de cromossomo para um aglomerado com três átomos.

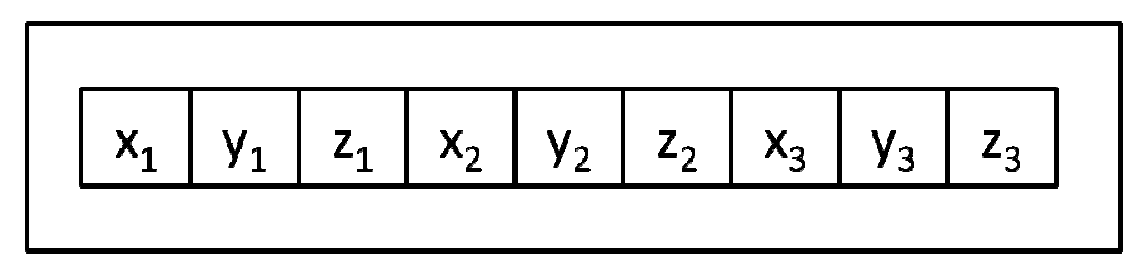

Figura 4.1. Cromossomo de um aglomerado atômico para o AG.

O AG foi criado através do pacote Global Optimization Toolbox do MATLAB. O potencial de Morse foi implementado e é chamado pelo toolbox. Conforme descrito na seção 3.3 , as unidades reduzidas de energia e comprimento, para este potencial, são definidas por $\epsilon=1 \mathrm{e}$ $r_{0}=1$.

Os parâmetros modificados, no toolbox, para a geração do código foram: 
- Tamanho da população: 50;

- Número de gerações: 10.000 ;

- Critério de parada: 10.000 gerações.

Os operadores utilizados, no AG foram:

- Migração: 20\% - especifica quantos indivíduos são copiados de uma subpopulação para outra subpopulação. Os melhores indivíduos de uma subpopulação subtitui os piores indivíduos da outra subpopulação.

- Cruzamento: $80 \%$;

- Mutação: adaptive feasible - gera posições aleatórias com direções adaptativas em relação à última geração bem ou mal sucedida. Os limites de $x, y$ e $z$ foram limitados entre -1 e 1 .

\subsection{2}

\section{Otimização por Programação Genética}

Assim como na otimização por AG, foram utilizados três genes para representar a posição $x, y \mathrm{e} z$ de cada átomo. Mas, nesta abordagem, o valor de cada gene é determinado por um programa. Logo o tamanho do cromossomo também é igual a $3 N$, onde $N$ é o número total de átomos. A figura 4.2 mostra um exemplo de cromossomo do OPG para um aglomerado com três átomos. Para a otimização por OPG, os valores de $x, y \mathrm{e} z$ não foram limitados, a limitação dos valores está nos valores dos terminais de cada programa, conforme a tabela 4.1.

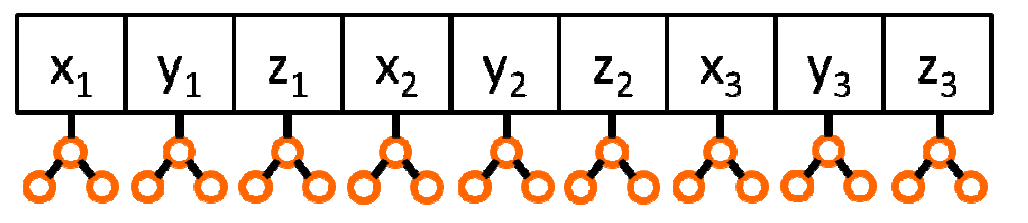

Figura 4.2. Cromossomo de um aglomerado atômico para o OPG. 


\begin{tabular}{cc}
\hline \hline Terminais & Funções \\
\hline Constantes entre \\
{$[-0,125 ; 0,125]$.} & Soma, subtração e produto. \\
\hline
\end{tabular}

Tabela 4.1. Terminais e funções do OPG.

O intervalo dos terminais foi definido através de testes de desempenho do OPG, e o mesmo apresentou os melhores resultados. Os intervalos testados foram: $[-10 ; 10],[-1 ; 1],[-0,5 ; 0,5],[-0,25 ; 0,25]$ e $[-0,125$; $0,125]$.

Este algoritmo foi desenvolvido utilizando elementos da biblioteca GPTIPS [34] de PGMG para o MATLAB. As principais configurações do OPG estão detalhadas na tabela 4.2.

\begin{tabular}{cc}
\hline \hline Característica do Algoritmo & Parâmetro \\
\hline Tamanho da população & 50 \\
Altura máxima da árvore & 3 \\
Máximo de nós por árvore & Não há um número \\
máximo & 3 \\
Número de casas decimais em cada nó & 10.000 \\
Número limite de gerações & 50 \\
Indivíduos participando no torneio & $35 \%$ \\
Probabilidade de cruzamento de baixo nível & $100 \%$ \\
Probabilidade de cruzamento de alto nível & $60 \%$ \\
Probabilidade de mutação & $5 \%$ \\
Probabilidade de clonagem & $2 \%$ \\
Taxa de elitismo & \\
\hline
\end{tabular}

Tabela 4.2. Principais configurações do OPG.

\section{3}

\section{Resultados e discussões}

\subsection{1}

\section{Potencial de Morse}

Para validação da implementação do potencial de Morse, os aglomerados encontrados por Doye e Wales [10] foram utilizados como entrada do programa que calcula a energia através deste potencial. As 
tabelas 4.3, 4.4, 4.5 e 4.6 apresentam os valores calculados neste trabalho ( $\left.E_{\text {calc }}\right)$ e os valores da energia mínima global (EMG), encontrados por Doye e Wales, para os aglomerados indicados nas tabelas. Para esta validação, só foram utilizados os aglomerados listados nas tabelas 4.3, $4.4,4.5$ e 4.6, porque estes são os únicos aglomerados com EMG disponíveis em [24].

Os resultados mostram que o potencial de Morse foi implementado de forma correta, encontrando a mesma energia para todos os aglomerados disponíveis em [24].

\begin{tabular}{ccc}
\hline \hline $\begin{array}{c}\text { Número de } \\
\text { Átomos }\end{array}$ & EMG & Ecalc \\
\hline 11 & $-37,930817$ & $-37,930817$ \\
14 & $-56,754744$ & $-56,754744$ \\
15 & $-63,162119$ & $-63,162119$ \\
16 & $-69,140648$ & $-69,140648$ \\
17 & $-75,662417$ & $-75,662417$ \\
18 & $-82,579266$ & $-82,579266$ \\
\hline
\end{tabular}

Tabela 4.3. Resultado do cálculo de energia dos aglomerados ( $E_{\text {calc }}$ que apresentaram energia mínima global (EMG) em [10], $\operatorname{com} \rho_{0}=3$. As energias estão em $\epsilon$.

\begin{tabular}{ccc}
\hline \hline \multirow{2}{*}{ Número de Átomos } & \multicolumn{2}{c}{$\rho_{0}=6$} \\
& EMG & Ecalc \\
\hline 5 & $-9,044930$ & $-9,044930$ \\
6 & $-12,487810$ & $-12,487809$ \\
7 & $-16,207580$ & $-16,207580$ \\
8 & $-19,327420$ & $-19,327420$ \\
9 & $-23,417190$ & $-23,417190$ \\
10 & $-27,473283$ & $-27,473283$ \\
11 & $-31,521880$ & $-31,521880$ \\
12 & $-36,400278$ & $-36,400278$ \\
13 & $-42,439863$ & $-42,439863$ \\
14 & $-45,619277$ & $-45,619277$ \\
15 & $-49,748409$ & $-49,748409$ \\
16 & $-53,845835$ & $-53,845835$ \\
17 & $-57,941386$ & $-57,941386$ \\
18 & $-62,689245$ & $-62,689245$ \\
19 & $-68,492285$ & $-68,492285$ \\
20 & $-72,507782$ & $-72,507782$ \\
21 & $-76,529139$ & $-76,529139$ \\
22 & $-81,136735$ & $-81,136735$ \\
23 & $-86,735494$ & $-86,735494$ \\
24 & $-90,685398$ & $-90,685398$ \\
25 & $-95,127899$ & $-95,127899$ \\
\hline
\end{tabular}

Tabela 4.4. Resultado do cálculo de energia dos aglomerados ( $\left.E_{c a l c}\right)$ que apresentaram energia mínima global (EMG) em [10], $\operatorname{com} \rho_{0}=6$. As energias estão em $\epsilon$. 


\begin{tabular}{ccc}
\hline \hline $\begin{array}{c}\text { Número de } \\
\text { Átomos }\end{array}$ & EMG & $\rho_{0}=10$ \\
\hline 21 & $-69,449904$ & Ecalc \\
22 & $-73,494292$ & $-69,449904$ \\
23 & $-78,325380$ & $-73,494292$ \\
24 & $-82,370214$ & $-82,325380$ \\
25 & $-86,989688$ & $-86,989688$ \\
\hline \hline
\end{tabular}

Tabela 4.5. Resultado do cálculo de energia dos aglomerados (Ecalc) que apresentaram energia mínima global (EMG) em [10], com $\rho_{0}=10$. As energias estão em $\epsilon$.

\begin{tabular}{ccc}
\hline \hline $\begin{array}{c}\text { Número de } \\
\text { Átomos }\end{array}$ & EMG & $\rho_{0}=14$ \\
\hline 11 & $-29,596054$ & Ecalc \\
\hline
\end{tabular}

Tabela 4.6. Resultado do cálculo de energia do aglomerado (Ecalc) que apresentou energia mínima global (EMG) em [10], com $\rho_{0}=14$. A energia está em $\epsilon$.

\subsection{2}

\section{Resultados das otimizações}

Dez simulações foram realizadas para cada aglomerado e para cada valor do parâmetro $\rho_{0}(3,6,10$ e 14), tanto para o AG, quanto para o OPG (total de 80 simulações por aglomerado, sendo 40 utilizando AG e 40 utilizando OPG). Foi selecionado o melhor indivíduo (de menor energia) de cada uma das dez simulações. A energia de cada aglomerado pode ser observada nas tabelas 4.7 e 4.8 .

\begin{tabular}{|c|c|c|c|c|}
\hline \multirow{2}{*}{$\begin{array}{l}\text { Número de } \\
\text { Átomos }\end{array}$} & \multicolumn{2}{|c|}{$\rho_{0}=3$} & \multicolumn{2}{|c|}{$\rho_{0}=6$} \\
\hline & $A G$ & OPG & $A G$ & OPG \\
\hline 5 & $-9,299501$ & $-9,299499$ & $-9,044930$ & $-9,044926$ \\
\hline 6 & $-13,544229$ & $-13,544226$ & $-12,487809$ & $-12,487801$ \\
\hline 7 & $-17,552961$ & $-17,552948$ & $-16,207580$ & $-15,563749$ \\
\hline 8 & $-22,042901$ & $-22,042881$ & $-19,327420$ & $-19,327377$ \\
\hline 9 & $-26,778449$ & $-26,778280$ & $-23,417190$ & $-23,417140$ \\
\hline 10 & $-31,888630$ & $-31,888551$ & $-26,579761$ & $-27,473182$ \\
\hline 11 & $-37,930817$ & $-37,930325$ & $-29,705933$ & $-31,521813$ \\
\hline 12 & $-44,097880$ & $-44,097576$ & $-34,755961$ & $-36,400096$ \\
\hline 13 & $-51,737046$ & $-51,737000$ & $-38,780072$ & $-42,439702$ \\
\hline 14 & $-56,754744$ & $-56,754270$ & $-43,425813$ & $-45,618875$ \\
\hline 15 & $-63,162119$ & $-63,161728$ & $-49,748401$ & $-49,748049$ \\
\hline 16 & $-69,140644$ & $-69,137488$ & $-51,608585$ & $-53,836911$ \\
\hline 17 & $-75,662395$ & $-75,634476$ & $-57,800365$ & $-57,792658$ \\
\hline 18 & $-82,579246$ & $-82,496089$ & $-59,427205$ & $-62,549657$ \\
\hline 19 & $-90,647461$ & $-90,646135$ & $-65,181178$ & $-65,959578$ \\
\hline 20 & $-97,417366$ & $-97,416557$ & $-67,639413$ & $-68,849328$ \\
\hline 21 & $-104,311351$ & $-104,191245$ & $-70,686907$ & $-75,552225$ \\
\hline 22 & $-111,514209$ & $-112,006988$ & $-77,435919$ & $-80,407699$ \\
\hline 23 & $-120,782194$ & $-120,783845$ & $-77,855395$ & $-83,745726$ \\
\hline 24 & $-127,882055$ & $-127,630162$ & $-84,024545$ & $-87,920545$ \\
\hline 25 & $-134,533491$ & $-135,392191$ & $-85,999200$ & $-93,592738$ \\
\hline
\end{tabular}

Tabela 4.7. Valor da energia encontrado pelos métodos OPG e AG para cada aglomerado de carbono, com $\rho_{0}$ igual a 3 e 6 . As energias estão em $\epsilon$. 


\begin{tabular}{|c|c|c|c|c|}
\hline \multirow{2}{*}{$\begin{array}{l}\text { Número de } \\
\text { Átomos }\end{array}$} & \multicolumn{2}{|c|}{$\rho_{0}=10$} & \multicolumn{2}{|c|}{$\rho_{0}=14$} \\
\hline & $\mathrm{AG}$ & $\mathrm{OPG}$ & $A G$ & OPG \\
\hline 5 & $-9,003565$ & $-9,003551$ & $-9,000283$ & $-9,000195$ \\
\hline 6 & $-12,009683$ & $-12,094817$ & $-12,000744$ & $-12,017942$ \\
\hline 7 & $-15,018345$ & $-15,956416$ & $-15,001206$ & $-15,882874$ \\
\hline 8 & $-18,964638$ & $-18,964383$ & $-16,001339$ & $-18,883247$ \\
\hline 9 & $-21,972863$ & $-22,850322$ & $-19,015258$ & $-21,883932$ \\
\hline 10 & $-23,037256$ & $-25,858090$ & $-16,049341$ & $-24,660595$ \\
\hline 11 & $-28,867862$ & $-30,264536$ & $-27,135065$ & $-27,441391$ \\
\hline 12 & $-30,979465$ & $-34,356184$ & $-28,962890$ & $-30,187665$ \\
\hline 13 & $-33,873941$ & $-39,661474$ & $-24,143754$ & $-36,969485$ \\
\hline 14 & $-36,859769$ & $-41,228201$ & $-29,232867$ & $-38,837718$ \\
\hline 15 & $-35,903383$ & $-46,471008$ & $-28,076150$ & $-41,281054$ \\
\hline 16 & $-43,370977$ & $-49,284231$ & $-33,056896$ & $-44,815148$ \\
\hline 17 & $-44,187954$ & $-51,591560$ & $-34,171628$ & $-46,745271$ \\
\hline 18 & $-47,084845$ & $-56,678397$ & $-34,119716$ & $-51,476892$ \\
\hline 19 & $-47,611990$ & $-58,841529$ & $-37,757211$ & $-56,184906$ \\
\hline 20 & $-50,981516$ & $-60,990606$ & $-47,141645$ & $-57,011622$ \\
\hline 21 & $-52,037431$ & $-67,107567$ & $-50,014414$ & $-58,561942$ \\
\hline 22 & $-62,774124$ & $-70,210502$ & $-57,213230$ & $-64,557325$ \\
\hline 23 & $-60,213285$ & $-74,707910$ & $-49,999962$ & $-68,115399$ \\
\hline 24 & $-61,557158$ & $-74,329999$ & $-41,145319$ & $-70,665622$ \\
\hline 25 & $-66,301765$ & $-80,945159$ & $-52,684074$ & $-74,518828$ \\
\hline
\end{tabular}

Tabela 4.8. Valor da energia encontrado pelos métodos OPG e AG para cada aglomerado de carbono, com $\rho_{0}$ igual a 10 e 14. As energias estão em $\epsilon$.

Os gráficos das figuras 4.3, 4.4, 4.5 e 4.6 mostram a energia global mínima (EMG) e as energias obtidas pelo $A G$ e pelo $O P G$, com o número de átomos dos aglomerados de carbono, para cada valor do parâmetro de alcance. As energias mínimas globais podem ser encontradas em [10].

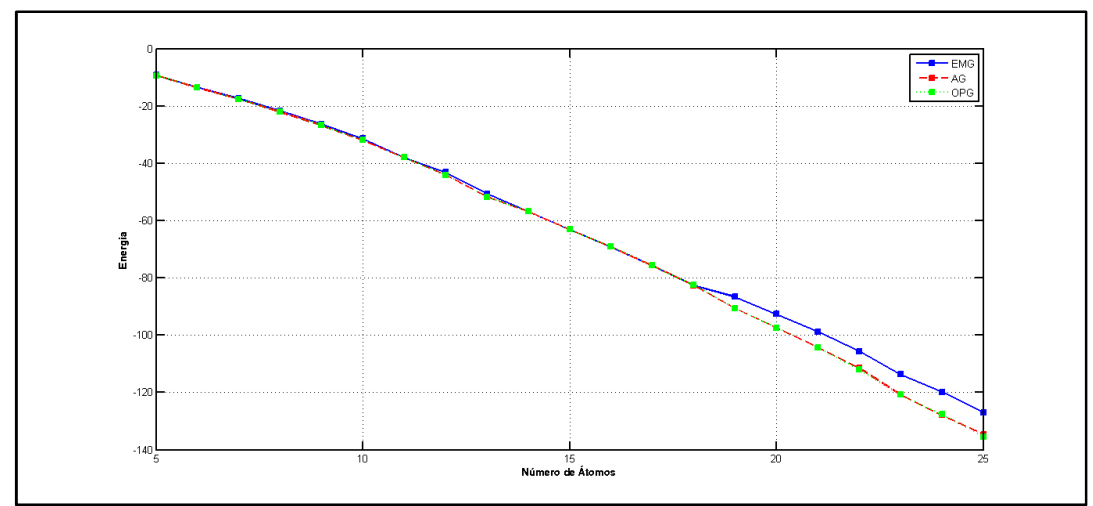

Figura 4.3. Gráfico da energia dos aglomerados, variando o número de átomos de 5 a 25, pelo AG, OPG e a energia mínima global (EMG), para $\rho_{0}=3$. As energias estão em $\epsilon$. 


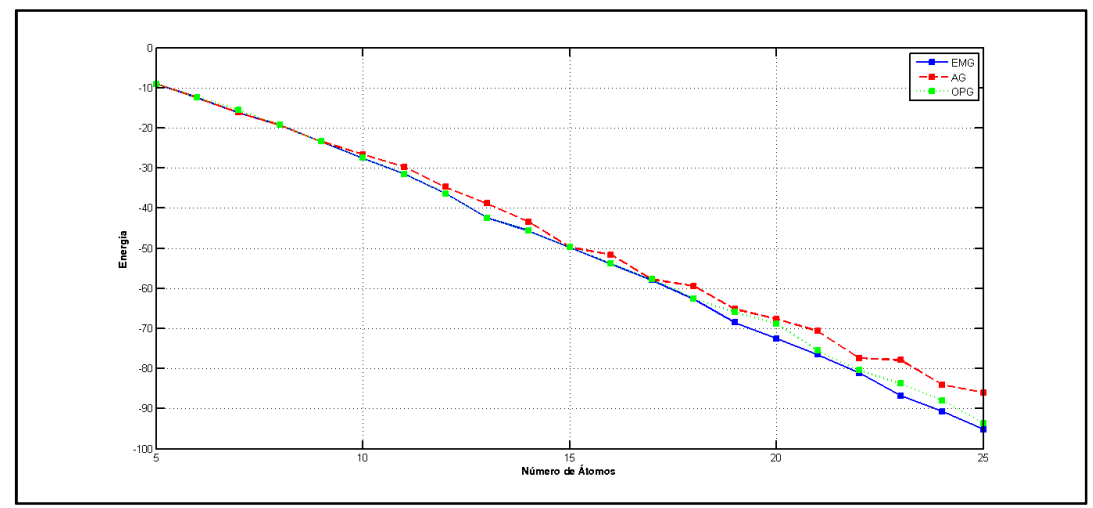

Figura 4.4. Gráfico da energia dos aglomerados, variando o número de átomos de $5 \mathrm{a}$ 25, pelo $A G, O P G$ e a energia mínima global (EMG), para $\rho_{0}=6$. As energias estão em $\epsilon$.

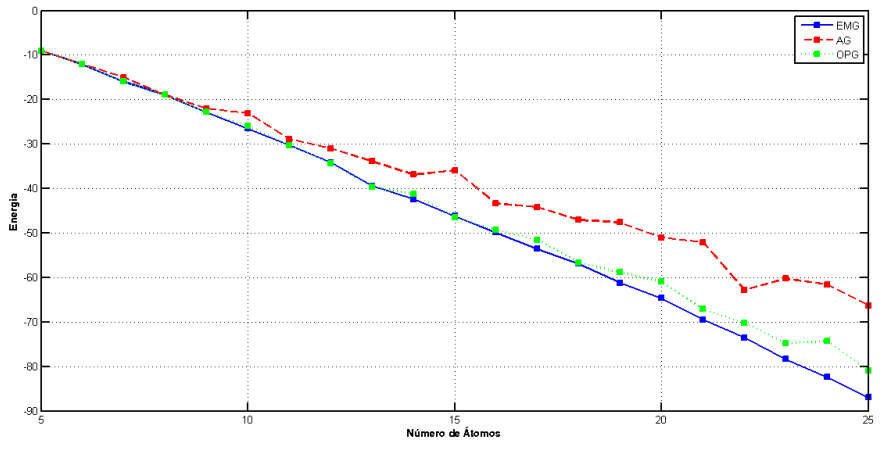

Figura 4.5. Gráfico da energia dos aglomerados, variando o número de átomos de $5 \mathrm{a}$ 25 , pelo $A G, O P G$ e a energia mínima global (EMG), para $\rho_{0}=10$. As energias estão em $\epsilon$.

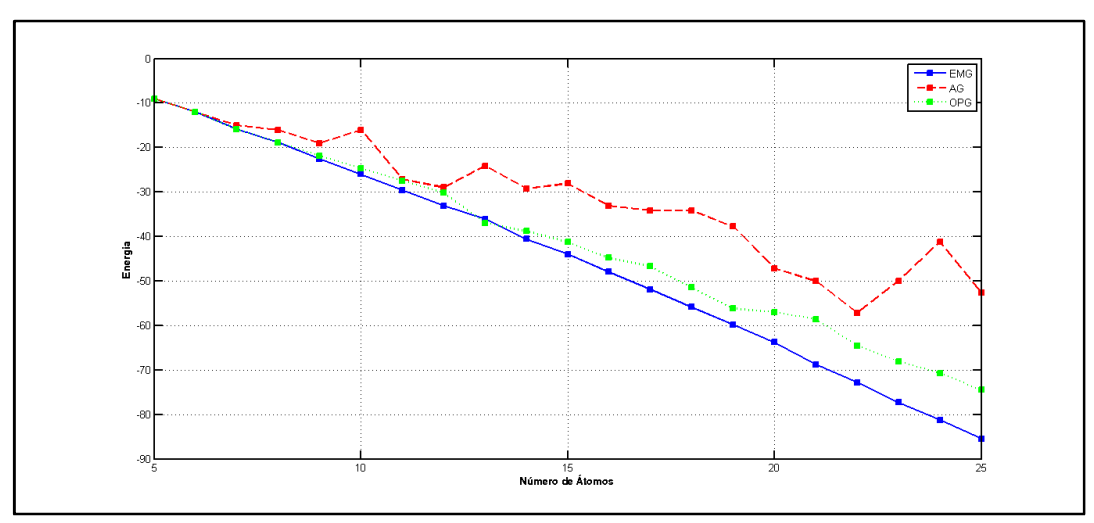

Figura 4.6. Gráfico da energia dos aglomerados, variando o número de átomos de 5 a 25, pelo $A G, O P G$ e a energia mínima global (EMG), para $\rho_{0}=14$. As energias estão em $\epsilon$. 
A figura 4.3 mostra que os resultados obtidos para $\rho_{0}=3$, através do $A G$ e do OPG foram muito próximos da energia mínima global (EMG), conseguindo alcançá-la em alguns aglomerados. Comparando os dois métodos de otimização, é possível notar uma ligeira superação do $A G$ em termos das enegias obtidas, porém a diferença só é observada a partir da quarta casa decimal. Ou seja, os dois métodos levaram a soluções muito perto dos mínimos globais, porém, na média, o AG foi sutilmente superior na otimização local. No entanto, esse comportamento não é garantido, visto que para os aglomerados de 22, 23 e 25 átomos, o OPG encontrou energias menores do que o AG. Pode-se considerar que os dois métodos foram capazes de encontrar os mínimos globais visto que essas diferenças de energia são muito pequenas, e qualquer método de otimização local poderia ser utilizado, posteriormente, para levar essa diferença de energia a zero (de acordo com os critérios de convergência estabelecidos). O gráfico da figura 4.7 mostra, de forma mais clara, a diferença entre os valores destas energias.

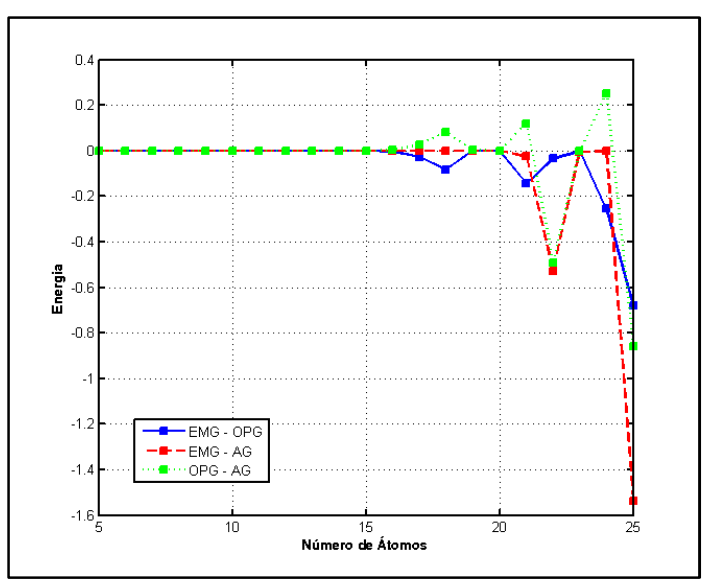

Figura 4.7. Gráfico das diferenças de energias dos aglomerados, variando o número de átomo de 5 a 25 , com $\rho_{0}=3$. As energias estão em $\epsilon$.

Considerando o potencial em que $\rho_{0}=6$, a figura 4.4 mostra que, com o aumento do número de átomos dos aglomerados de carbono, os resultados obtidos através do OPG são mais próximos da energia mínima global (EMG), do que os obtidos pelo AG. Para os aglomerados de 5 a 9 átomos, o $A G$ foi capaz de encontrar a EMG. Comparando os dois métodos, o OPG apresentou resultados melhores do que o AG. O gráfico 
da figura 4.8 mostra, de forma mais clara, a diferença entre os valores destas energias.

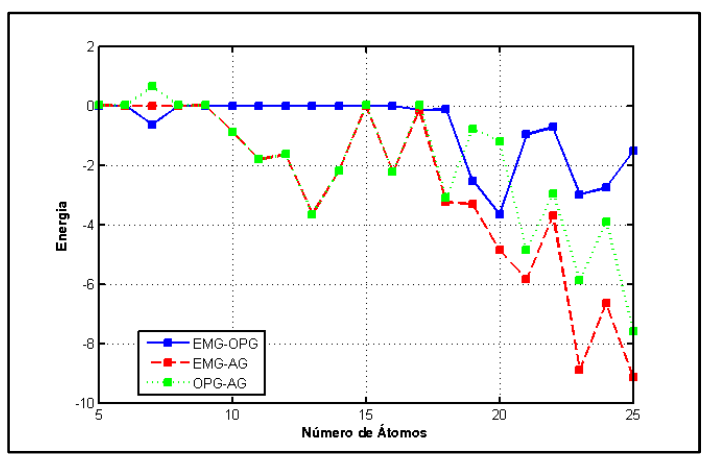

Figura 4.8. Gráfico das diferenças de energias dos aglomerados, variando o número de átomos de 5 a 25, com $\rho_{0}=6$. As energias estão em $\epsilon$.

Observando a figura 4.5, é possível verificar que os resultados obtidos para $\rho_{0}=10$ através do OPG foram mais próximos da energia mínima global do que os obtidos pelo AG. O AG foi capaz de encontrar a EMG apenas para os aglomerados de 5 e 8 átomos. Comparando os dois métodos, o OPG apresentou resultados significativamente melhores do que $0 \mathrm{AG}$, principalmente para os aglomerados maiores. O gráfico da figura 4.9 mostra, de forma mais clara, a diferença entre os valores destas energias.

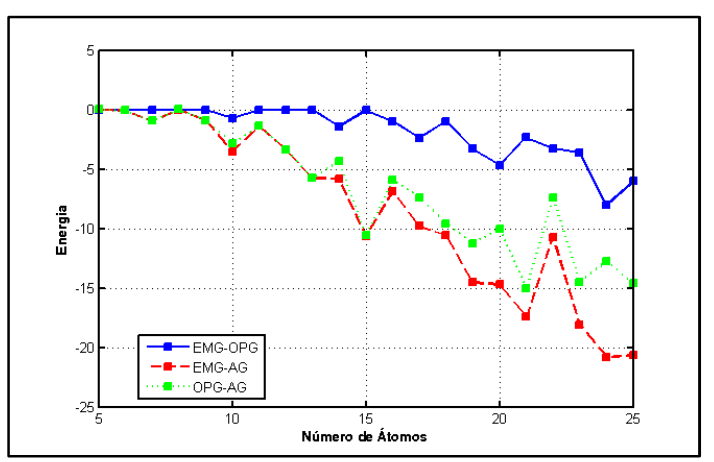

Figura 4.9. Gráfico da diferença de energias dos aglomerados, variando o número de átomos de 5 a 25 , com $\rho_{0}=10$. As energias estão em $\epsilon$.

A figura 4.6 mostra que os resultados obtidos para $\rho_{0}=14$. O AG encontrou a EMG apenas para o aglomerado de 5 átomos. Comparando os dois métodos, o OPG apresentou resultados significativamente 
melhores do que o AG, exceto para o aglomerado de 5 átomos. $O$ gráfico da figura 4.10 mostra, de forma mais clara, a diferença entre os valores destas energias.

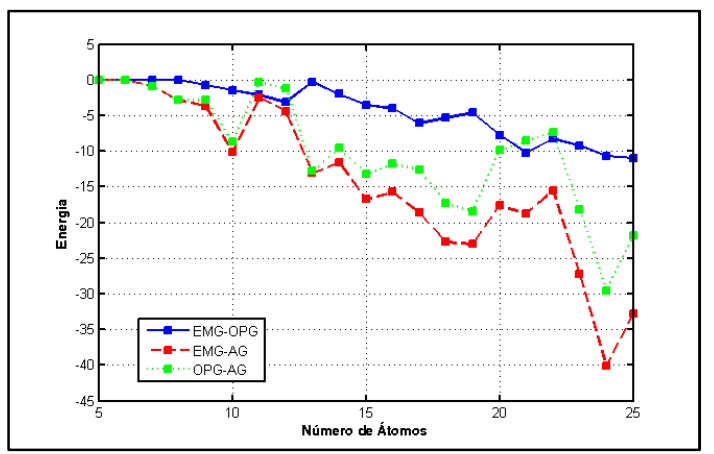

Figura 4.10. Gráfico das diferenças de energias dos aglomerados, variando o número de átomos de 5 a 25 , com $\rho_{0}=14$. As energias estão em .

Por se tratar de métodos estocásticos, a comparação do OPG com - AG não pode ser realizada apenas pelos melhores indivíduos encontrados. Para uma comparação mais consistente, pode-se utilizar o método Wilcoxon Signed Rank [35], onde os métodos de otimização são comparados através da mediana de todas as simulações.

A mediana é calculada colocando-se todos os valores de uma amostra em ordem crescente, ou decrescente, e selecionando o valor que ocupa a posição central, se a quantidade de valores da amostra for ímpar, ou a média dos dois valores centrais, se a quantidade de valores da amostra for par [36]. Desta maneira, a mediana separa a metade inferior da amostra da metade superior.

As tabelas 4.9 e 4.10 mostram as medianas das energias das dez simulações realizadas por cada método de otimização utilizado, AG e OPG. 


\begin{tabular}{|c|c|c|c|c|}
\hline \multirow{2}{*}{$\begin{array}{l}\text { Número de } \\
\text { Átomos }\end{array}$} & \multicolumn{2}{|c|}{$\rho_{0}=3$} & \multicolumn{2}{|c|}{$\rho_{0}=6$} \\
\hline & $A G$ & OPG & $A G$ & OPG \\
\hline 5 & $-9,299501$ & $-9,299496$ & $-9,044930$ & $-9,044912$ \\
\hline 6 & $-13,544229$ & $-13,544217$ & $-12,128034$ & $-12,307894$ \\
\hline 7 & $-17,387033$ & $-17,276399$ & $-15,215747$ & $-15,247476$ \\
\hline 8 & $-21,950232$ & $-22,042851$ & $-18,834200$ & $-19,161035$ \\
\hline 9 & $-26,610231$ & $-26,778052$ & $-22,427730$ & $-22,389137$ \\
\hline 10 & $-31,800483$ & $-31,888491$ & $-25,542103$ & $-26,358758$ \\
\hline 11 & $-37,666875$ & $-37,891188$ & $-29,654522$ & $-30,456450$ \\
\hline 12 & $-44,097880$ & $-44,094654$ & $-33,024240$ & $-36,399720$ \\
\hline 13 & $-51,737046$ & $-51,736970$ & $-36,719156$ & $-38,722765$ \\
\hline 14 & $-56,754737$ & $-56,753413$ & $-40,340895$ & $-44,284705$ \\
\hline 15 & $-63,119865$ & $-63,161198$ & $-44,775099$ & $-47,779970$ \\
\hline 16 & $-68,942738$ & $-68,945203$ & $-48,957910$ & $-51,530185$ \\
\hline 17 & $-75,217757$ & $-75,112477$ & $-53,192972$ & $-55,861010$ \\
\hline 18 & $-82,323476$ & $-81,558556$ & $-53,441736$ & $-59,760593$ \\
\hline 19 & $-89,301370$ & $-89,247010$ & $-59,990376$ & $-63,443126$ \\
\hline 20 & $-96,878841$ & $-96,045941$ & $-61,385589$ & $-67,319525$ \\
\hline 21 & $-103,826537$ & $-103,199715$ & $-65,545647$ & $-71,001795$ \\
\hline 22 & $-111,051886$ & $-110,539014$ & $-70,078275$ & $-76,378959$ \\
\hline 23 & $-118,845859$ & $-118,918362$ & $-67,869680$ & $-80,602929$ \\
\hline 24 & $-125,811747$ & $-126,280845$ & $-75,702161$ & $-84,862853$ \\
\hline 25 & $-134,005538$ & $-134,619232$ & $-81,325943$ & $-88,294734$ \\
\hline
\end{tabular}

Tabela 4.9. Valor da energia mediana encontrada pelos métodos OPG e AG para cada aglomerado de carbono, com $\rho_{0}$ igual a 3 e 6 . As energias estão em $\epsilon$.

\begin{tabular}{|c|c|c|c|c|}
\hline \multirow{2}{*}{$\begin{array}{l}\text { Número de } \\
\text { Átomos }\end{array}$} & \multicolumn{2}{|c|}{$\rho_{0}=10$} & \multicolumn{2}{|c|}{$\rho_{0}=14$} \\
\hline & $A G$ & OPG & $A G$ & OPG \\
\hline 5 & $-9,003565$ & $-9,003528$ & $-7,000211$ & $-9,000066$ \\
\hline 6 & $-12,009683$ & $-12,009580$ & $-7,510621$ & $-11,507338$ \\
\hline 7 & $-14,748036$ & $-15,098779$ & $-11,007272$ & $-14,508460$ \\
\hline 8 & $-17,023920$ & $-18,021310$ & $-12,502586$ & $-17,510589$ \\
\hline 9 & $-17,080459$ & $-20,878647$ & $-14,005947$ & $-20,074810$ \\
\hline 10 & $-20,574049$ & $-24,145777$ & $-13,011940$ & $-23,247908$ \\
\hline 11 & $-24,644783$ & $-28,556252$ & $-17,062651$ & $-25,834064$ \\
\hline 12 & $-23,154606$ & $-31,818814$ & $-18,019139$ & $-29,012133$ \\
\hline 13 & $-27,948099$ & $-35,691941$ & $-20,038578$ & $-31,912322$ \\
\hline 14 & $-31,169584$ & $-39,178594$ & $-25,514950$ & $-35,825807$ \\
\hline 15 & $-33,626757$ & $-42,032263$ & $-23,007048$ & $-39,764834$ \\
\hline 16 & $-38,155959$ & $-45,845350$ & $-24,005510$ & $-41,678141$ \\
\hline 17 & $-35,947091$ & $-48,251503$ & $-28,647226$ & $-44,858255$ \\
\hline 18 & $-32,999517$ & $-51,327980$ & $-24,531852$ & $-47,311988$ \\
\hline 19 & $-39,836612$ & $-55,944389$ & $-32,537993$ & $-50,883065$ \\
\hline 20 & $-37,293458$ & $-58,546087$ & $-30,572272$ & $-54,142708$ \\
\hline 21 & $-45,300679$ & $-62,506157$ & $-31,574229$ & $-55,784558$ \\
\hline 22 & $-44,507310$ & $-67,116800$ & $-35,147539$ & $-61,296960$ \\
\hline 23 & $-47,022109$ & $-70,795592$ & $-41,760637$ & $-62,291928$ \\
\hline 24 & $-51,429957$ & $-73,171089$ & $-36,626622$ & $-67,897178$ \\
\hline 25 & $-56,418985$ & $-78,276099$ & $-44,862793$ & $-70,896762$ \\
\hline
\end{tabular}

Tabela 4.10. Valor da mediana da energia encontrada pelos métodos OPG e AG para cada aglomerado de carbono, com $\rho_{0}$ igual a 10 e 14. As energias estão em $\epsilon$.

\section{A tabelas 4.11 e 4.12 mostram os valores da mediana das} medianas das simulações dos métodos de otimização.

\begin{tabular}{|c|c|c|c|}
\hline & $\rho_{0}=3$ & & $\rho_{0}=6$ \\
\hline GA & $\mathrm{OPG}$ & GA & $\mathrm{OPG}$ \\
\hline 19865 & $-63,161198$ & $-44,775099$ & $-47,779970$ \\
\hline
\end{tabular}

Tabela 4.11. Valor da mediana das medianas das energias encontradas pelos métodos OPG e AG dos aglomerados de carbono, com $\rho_{0}$ igual a 3 e 6 . As energias estão em $\epsilon$. 


\begin{tabular}{|c|c|c|c|}
\hline & $\rho_{0}=10$ & & $\rho_{0}=14$ \\
\hline GA & OPG & GA & $\mathrm{OPG}$ \\
\hline$-32,999517$ & $-42,032263$ & $-24,005510$ & $-39,764834$ \\
\hline
\end{tabular}

Tabela 4.12. Valor da mediana das medianas das energias encontradas pelos métodos OPG e AG dos aglomerados de carbono, com $\rho_{0}$ igual a 10 e 14. As energias estão em $\epsilon$.

A tabela 4.13 apresenta os resultados das comparações pelo método Wilcoxon Signed Rank.

\begin{tabular}{cccc}
\hline \hline$\rho_{0}=3$ & $\rho_{0}=6$ & $\rho_{0}=10$ & $\rho_{0}=14$ \\
\hline 0,000543 & 0,000106 & 0,000092 & 0,000060 \\
\hline
\end{tabular}

Tabela 4.13. Resultado da comparação entre os métodos AG e OPG, pelo método Wilcoxon Signed Rank.

Conforme o método Wilcoxon Signed Rank, para encontrar o melhor método, deve-se verificar o resultado da comparação entre os métodos (tabela 4.13). Se o valor for menor do que 5\%, a mediana das medianas (tabelas 4.11 e 4.12) que apresentar menor valor entre os dois métodos é o método que possui melhores resultados. Sendo assim, observando os resultados dos métodos utilizados, é possível observar que - OPG foi melhor do que o AG. O apêndice $A$ apresenta maiores informações sobre o método Wilcoxon Signed Rank.

As figuras $4.11,4.12,4.13$ e 4.14 apresentam a ordenação das energias encontradas pelas dez simulações realizadas pelo AG, para $\rho_{0}$ igual a 3, 6, 10 e 14, respectivamente. Já as figuras 4.15, 4.16, 4.17 e 4.18 apresentam a ordenação das energias encontradas pelas dez simulações realizadas pelo OPG, para $\rho_{0}$ igual a 3, 6, 10 e 14, respectivamente. Estas ordenações foram colocadas de forma crescente, para permitir a observação dos valores de energia encontrados por cada método, para cada aglomerado (de 5 a 25 átomos) e variando o valor de $\rho_{0}$. 


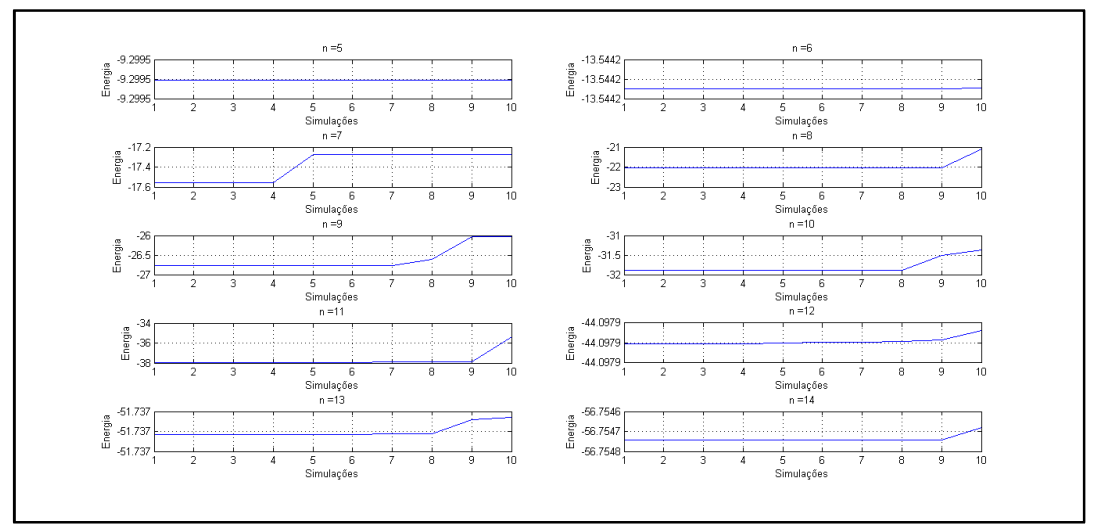

Figura 4.11. Gráficos da ordenação das energias para as dez simulações realizadas pelo $\mathrm{AG}$, com $\rho_{0}=3$, para o número de átomos (n) de 5 a 25. As energias estão em $\epsilon$.

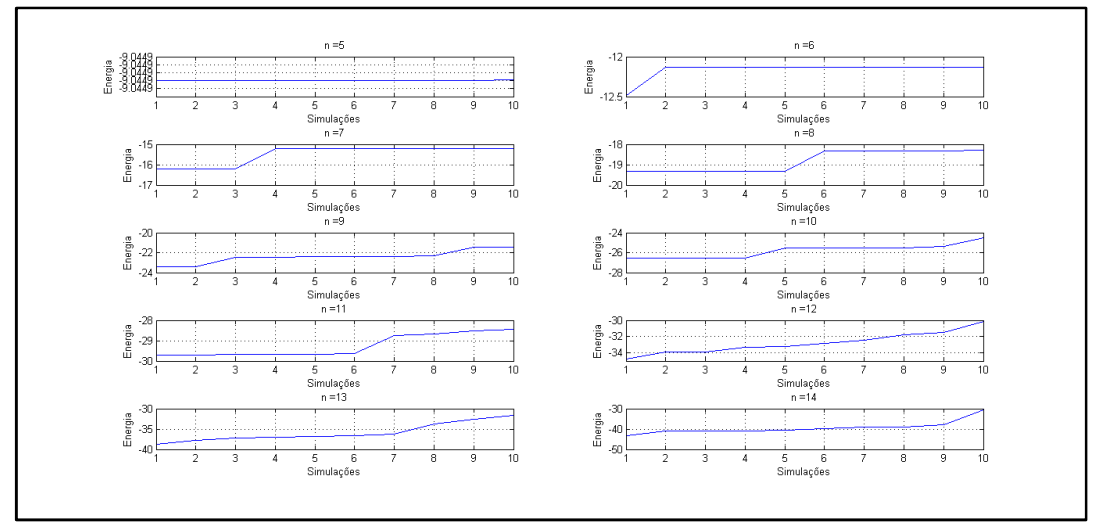

Figura 4.12. Gráficos da ordenação das energias para as dez simulações realizadas pelo $\mathrm{AG}, \operatorname{com} \rho_{0}=6$, para o número de átomos (n) de 5 a 25. As energias estão em $\epsilon$.

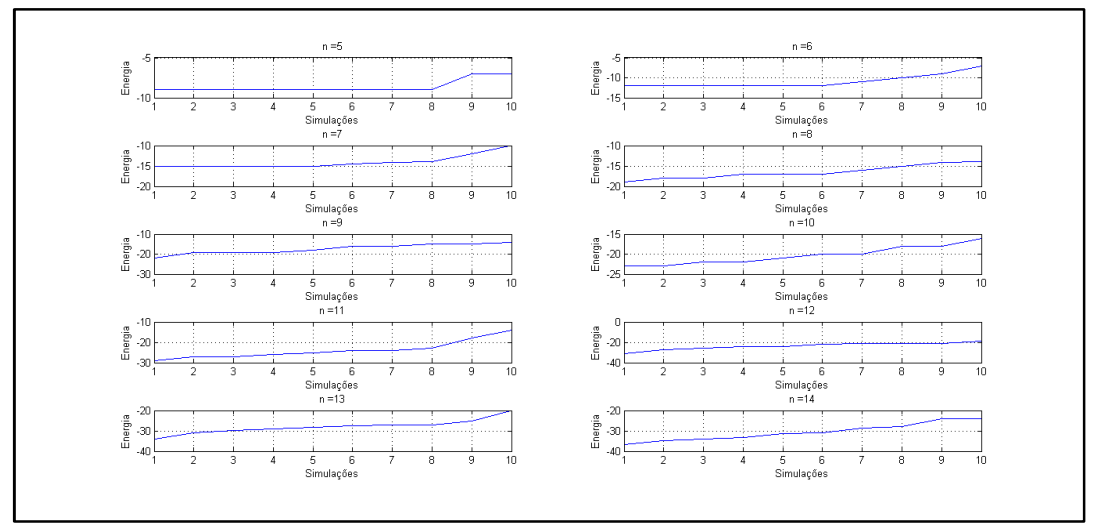

Figura 4.13. Gráficos da ordenação das energias para as dez simulações realizadas pelo $\mathrm{AG}$, com $\rho_{0}=10$, para o número de átomos (n) de 5 a 25. As energias estão em $\epsilon$. 


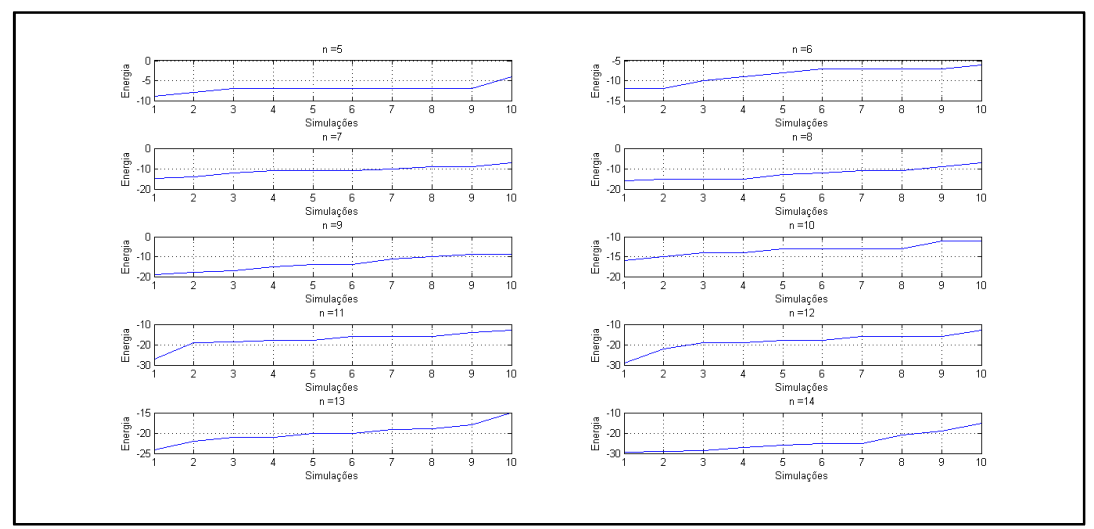

Figura 4.14. Gráficos da ordenação das energias para as dez simulações realizadas pelo $\mathrm{AG}$, com $\rho_{0}=14$, para o número de átomos (n) de 5 a 25. As energias estão em $\epsilon$.

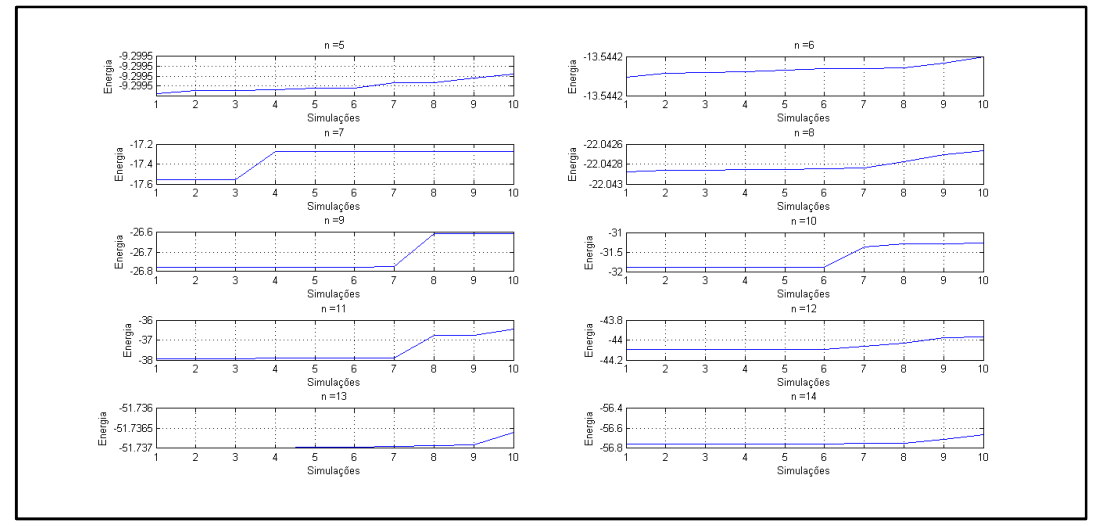

Figura 4.15. Gráficos da ordenação das energias para as dez simulações realizadas pelo OPG, com $\rho_{0}=3$, para o número de átomos (n) de 5 a 25. As energias estão em $\epsilon$.

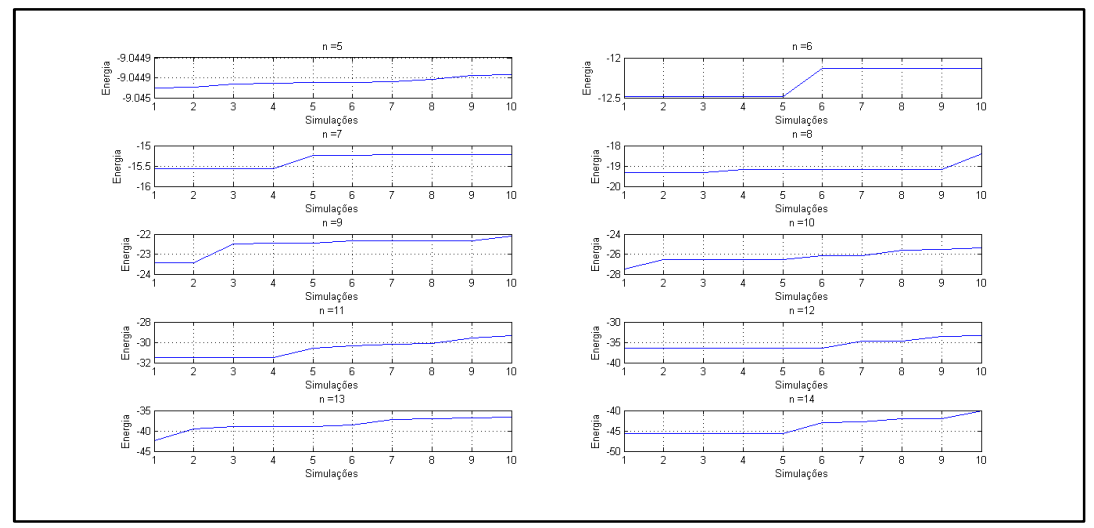

Figura 4.16. Gráficos da ordenação da energia para as dez simulações realizadas pelo OPG, com $\rho_{0}=6$, para o número de átomos (n) de 5 a 25. As energias estão em $\epsilon$. 


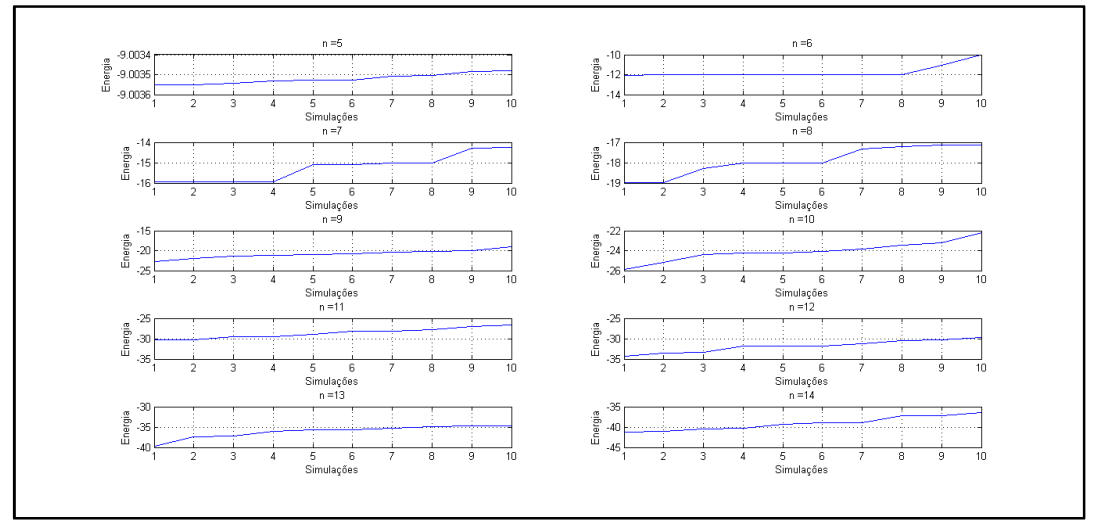

Figura 4.17. Gráficos da ordenação das energias para as dez simulações realizadas pelo OPG, com $\rho_{0}=10$, para o número de átomos (n) de 5 a 25. As energias estão em $\epsilon$.

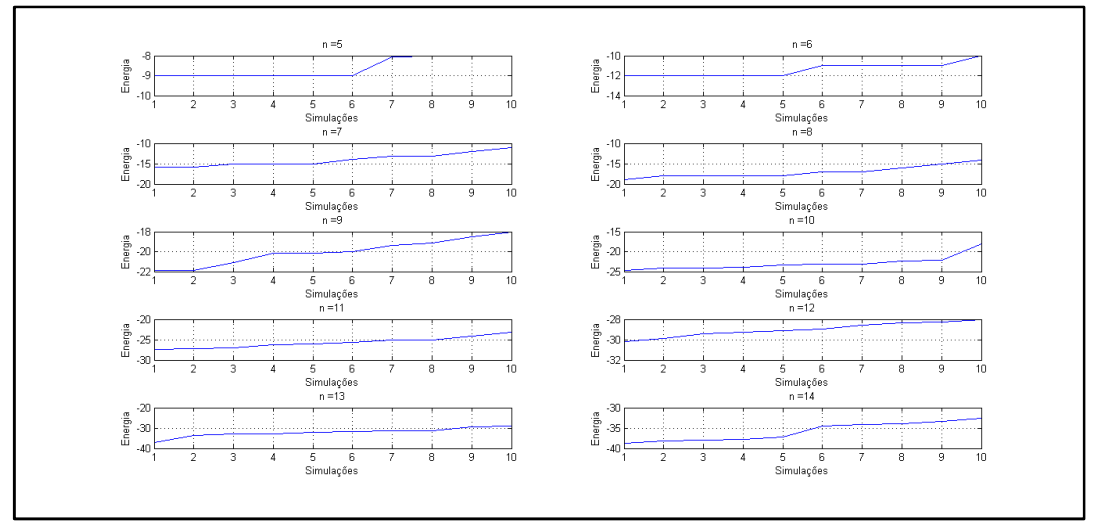

Figura 4.18. Gráficos da ordenação da energia para as dez simulações realizadas pelo OPG, com $\rho_{0}=14$, para o número de átomos (n) de 5 a 25. As energias estão em $\epsilon$.

\subsection{3}

\section{Estrutura dos aglomerados}

Uma análise estrutural dos aglomerados se faz necessária para verificar se os métodos de otimização utilizados neste trabalho encontraram aglomerados com geometrias estruturais pertinentes. Para esta análise, foi utilizada o método Kabsch [37], que minimiza o desvio médio quadrático (RMSD - root mean square deviation), realizando uma comparação entre duas estruturas. Este método sobrepõe os centroides das estruturas, eliminando, assim, problemas com translações, e calcula a matriz de rotação que melhor sobrepõe as duas estruturas.

As tabelas $4.14,4.15,4.16$ e 4.17 apresentam os resultados do método Kabsch (RMSD) entre os aglomerados encontrados pelo $A G$ e os 
aglomerados com energia mínima global (EMG), e entre os aglomerados encontrados pelo OPG e os aglomerados com EMG. Para estas comparações, foram utilizados todos os aglomerados disponibilizados por Doye e Wales, encontrados em [9] e [10], que possuem energia mínima global.

\begin{tabular}{ccc}
\hline \hline Número de & \multicolumn{2}{c}{$\rho_{0}=3$} \\
Átomos & RMSD (AG e EMG) & RMSD (OPG e EMG) \\
\hline 11 & 0,088250 & 0,091546 \\
14 & 0,545093 & 0,113190 \\
15 & 0,130442 & 0,116740 \\
16 & 0,385710 & 0,070407 \\
17 & 0,277009 & 0,344743 \\
18 & 0,333078 & 0,326411 \\
\hline
\end{tabular}

Tabela 4.14. RMSD entre os aglomerados com energia mínima global (EMG) e os aglomerados encontrados pelos métodos AG e OPG, para $\rho_{0}=3$.

\begin{tabular}{ccc}
\hline \hline $\begin{array}{c}\text { Número de } \\
\text { Átomos }\end{array}$ & \multicolumn{3}{c}{$\rho_{0}=6$} \\
\hline 5 & 0,107129 & 0,137432 \\
6 & 0,145285 & 0,023948 \\
7 & 0,616687 & 0,074895 \\
8 & 0,575669 & 0,410390 \\
9 & 0,203757 & 0,127468 \\
10 & 0,384966 & 0,318251 \\
11 & 0,302639 & 0,121403 \\
12 & 0,222745 & 0,140841 \\
13 & 0,690908 & 0,028753 \\
14 & 0,636535 & 0,476982 \\
15 & 0,737980 & 0,604375 \\
16 & 0,316219 & 0,374056 \\
17 & 0,410917 & 0,393918 \\
18 & 0,695030 & 0,598341 \\
19 & 0,375207 & 0,088226 \\
20 & 0,272732 & 0,289706 \\
21 & 0,668754 & 0,153434 \\
22 & 0,542651 & 0,211719 \\
23 & 0,566590 & 0,322299 \\
24 & 0,553065 & 0,631331 \\
25 & 0,884540 & 0,088331 \\
\hline
\end{tabular}

Tabela 4.15. RMSD entre os aglomerados com energia mínima global (EMG) e os aglomerados encontrados pelos métodos AG e OPG, para $\rho_{0}=6$.

\begin{tabular}{ccc}
\hline \hline Número de & \multicolumn{2}{c}{$\rho_{0}=10$} \\
Átomos & RMSD (AG e EMG) & RMSD (OPG e EMG) \\
\hline 21 & 0,709336 & 0,477574 \\
22 & 0,519797 & 0,291532 \\
23 & 0,534562 & 0,595848 \\
24 & 0,468348 & 0,582359 \\
25 & 1,186915 & 0,588293 \\
\hline
\end{tabular}

Tabela 4.16. RMSD entre os aglomerados com energia mínima global (EMG) e os aglomerados encontrados pelos métodos AG e OPG, para $\rho_{0}=10$. 


\begin{tabular}{ccc}
\hline \hline $\begin{array}{c}\text { Número de } \\
\text { Átomos }\end{array}$ & RMSD (AG e EMG) & $\rho_{0}=14$ \\
\hline 11 & 0,850384 & RMSD (OPG e EMG) \\
\hline 11 & 0,093077 \\
\hline
\end{tabular}

Tabela 4.17. RMSD entre os aglomerados com energia mínima global (EMG) e os aglomerados encontrados pelos métodos AG e OPG, para $\rho_{0}=14$.

Para fins de comparação, quanto mais próximo de zero o RMSD, maior é a similaridade com os aglomerados com energia mínima global. Sendo assim, pode-se afirmar que o OPG encontrou aglomerados com estruturas mais próximas dos aglomerados com energia mínima global do que os encontrados pelo AG, para a maioria dos casos.

As figuras 4.19 e 4.20 mostram os aglomerados encontrados pelos métodos de otimização que obtiveram o menor e maior valor de RMSD, respectivamente, ao lado do aglomerado com energia mínima global.

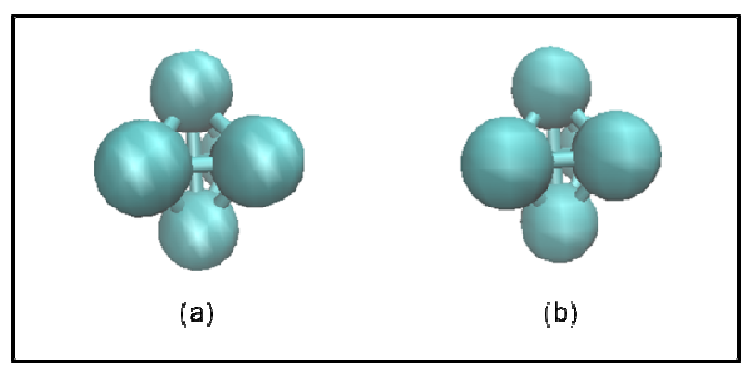

Figura 4.19. Aglomerados de carbono, com 6 átomos. (a) aglomerado encontrado pelo OPG, com $\rho_{0}=6$; (b) aglomerado com energia mínima global, com $\rho_{0}=6$.

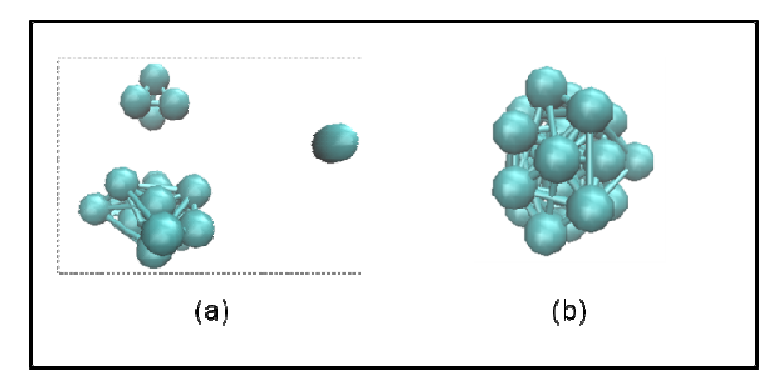

Figura 4.20. Aglomerados de carbono, com 25 átomos. (a) aglomerado encontrado pelo AG, com $\rho_{0}=10$; (b) aglomerado com energia mínima global, com $\rho_{0}=10$.

É possível observar que quando o RMSD possui um valor próximo de zero, os aglomerados são semelhantes; quando o valor do RMSD é 
maior, há diferenças maiores entre os aglomerados, o que descarta algumas solução encontradas pelo AG, como no caso da figura 4.20

Foi constatado, também, que apesar do AG ter sido desenvolvido com restrições de domínio para $x, y$ e $z$ para o intervalo $[-1,1]$, o método encontrou aglomerados com átomos em posições fora deste intervalo. Isto aconteceu porque os operadores geraram indivíduos com posições inválidas. Para solucionar este problema, é necessário um maior controle dos operadores genéticos.

Mesmo sem uma restrição de domínio para as posições dos átomos em $x, y$ e $z$ para o OPG, este método não apresentou nenhum aglomerado com posições de átomos inválidas em suas respostas. A única restrição imposta foi quanto aos valores assumidos pelas constantes dos programas (de -0.125 a 0.125 ). Ou seja, qualquer valor poderia ter sido gerado para as posições $x, y$ e $z$, e o OPG eliminou estes indivíduos automaticamente.

A figura 4.21 mostra o aglomerado encontrado pelo OPG, para o mesmo caso da figura 4.20, com 25 átomos e $\rho_{0}=10$. Neste caso, 0 RMSD é menor do que o da figura 4.20, e observa-se que o aglomerado possui uma geometria estrutural mais próxima do aglomerado de energia mínima global.

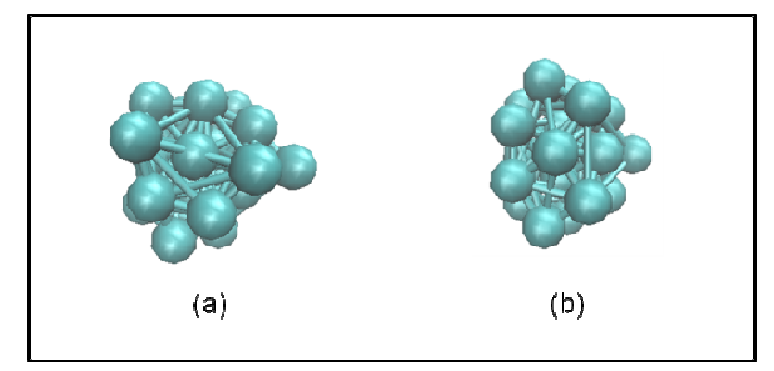

Figura 4.21. Aglomerados de carbono, com 25 átomos. (a) aglomerado encontrado pelo OPG, com $\rho_{0}=10$; (b) aglomerado com energia mínima global, com $\rho_{0}=10$.

\subsection{4}

\section{Tempo de simulação}

As figuras 4.22 e 4.23 mostram o tempo médio de execução por avaliação pelo AG e pelo OPG, respectivamente. Este tempo foi calculado 
através da média dos tempos de execução por avaliação, do melhor aglomerado encontrado, nas dez simulações, pelos métodos de otimização.

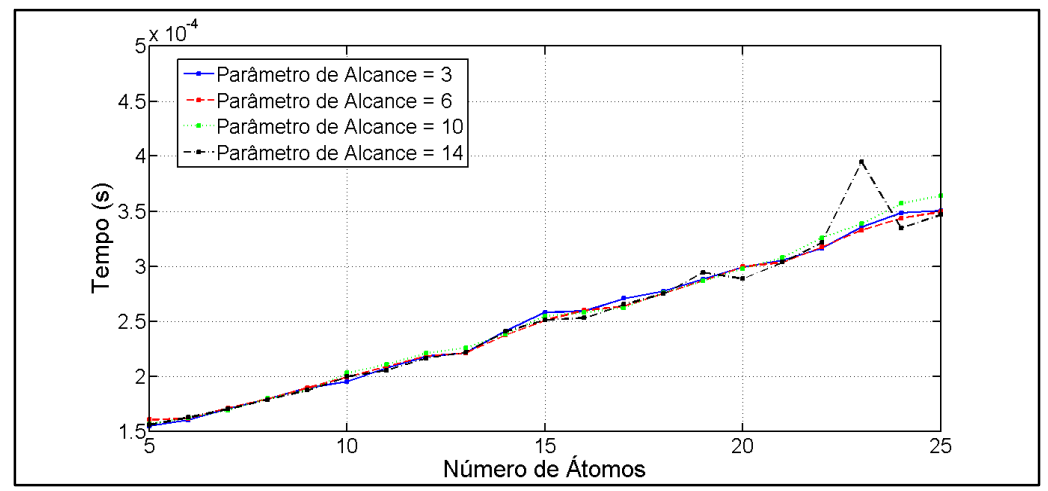

Figura 4.22. Tempo médio, em segundos, de execução por avaliação, variando o número de átomos do aglomerado de carbono, para o AG.

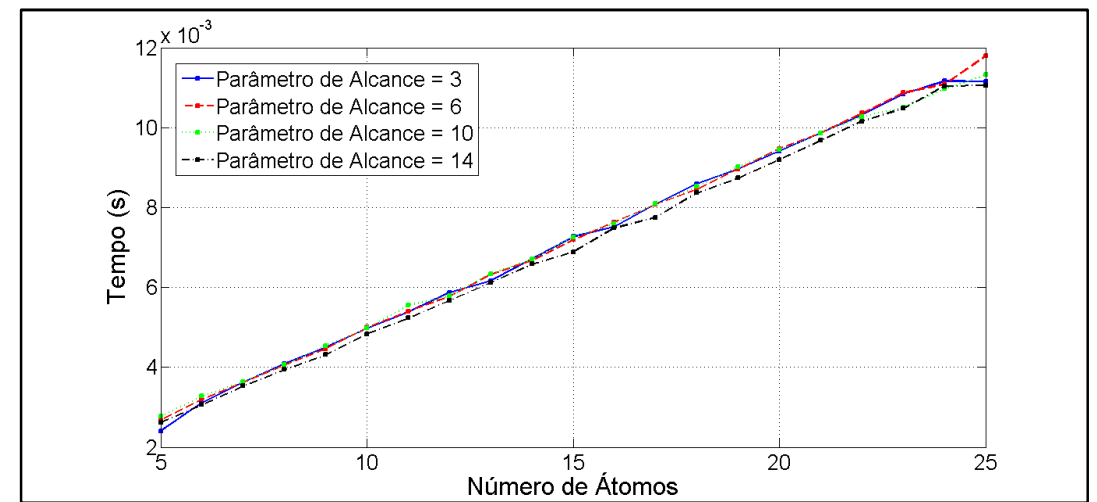

Figura 4.23. Tempo médio, em segundos, de execução por avaliação, variando o número de átomos do aglomerado de carbono, para o OPG.

Analisando os gráficos, é possível observar que o tempo execução de uma avaliação para o $A G$ é significativamente menor do que o do OPG. Esta superioridade por parte do AG já era esperada, pois a avaliação de cada indivíduo do OPG passa pela avaliação de todas as suas árvores para se determinar os valores de $x, y$ e $z$ dos átomos, enquanto no cromossomo do $A G$, estas posições já estão representadas diretamente (alelos). Além disso o método $A G$ já foi desenvolvido e otimizado pelo fabricante do MATLAB, enquanto o OPG foi desenvolvido em cima da biblioteca GPTIPS [34] de PGMG, para o MATLAB. 
A superioridade dos resultados do $O P G$ em relação ao $A G$ nas seções anteriores indica que uma melhoria na implementação para a redução do tempo de simulação do OPG se faz necessária e seria de grande utilidade para a área de simulação de aglomerados atômicos ou moleculares. 


\section{Conclusão e Trabalhos Futuros}

Este trabalho propôs a utilização do método de Otimização por Programação Genética para a otimização estrutural de aglomerados. Um Algoritmo Genético foi implementado, de forma independente, para permitir uma comparação entre os resultados dos dois métodos. Resultados já obtidos na literatura, também serviram como comparação para a validação do método $O P G$.

A otimização consistiu na minimização da energia para encontrar estruturas estáveis. O cálculo da energia foi realizado através do potencial de Morse, onde somente a alteração de um parâmetro (o parâmetro de alcance) é suficiente para alterar significativamente a superfície de energia potencial dos aglomerados. Foram realizadas dez simulações para cada aglomerado de carbono, com o número de átomos variando entre 5 e 25, e o parâmetro de alcance variando entre quatro valores. Estas simulações foram realizadas tanto para o método OPG, quanto para o AG, totalizando 1.680 simulações.

Constatou-se que os métodos de otimização são capazes de encontrar a energia mínima global para os menores aglomerados. Com o aumento do número de átomos, as energias encontradas pelo $A G$ se distanciam de forma mais rápida da energia mínima global, do que as energias encontradas pelo OPG.

Comparando os métodos OPG e AG implementados, o método OPG foi superior na grande maioria dos casos. Esta superioridade pôde ser constatada de duas maneiras. Primeiramente, o método encontrou um maior número de aglomerados de baixa energia, comprovado através do método Wilcoxon Signed Rank. Além disso, o OPG encontrou aglomerados com geometria estrutural mais próxima dos aglomerados conhecidos, análise feita através dos valores do RMSD.

$O$ método OPG se mostrou capaz de realizar a otimização estrutural de aglomerados, assim como $\circ \mathrm{AG}$, que já é utilizado em pesquisas da área. A comparação do OPG foi realizada com um $A G$ 
simples, sem a utilização de operadores específicos para aglomerados atômicos e moleculares, permitindo uma melhor avaliação da possibilidade da utilização deste novo método na área.

Em relação ao tempo de execução por avaliação, o AG foi superior ao OPG. Porém, esta diferença ocorre porque o OPG é um método recente e ainda precisa de otimizações em sua implementação. A superioridade do método OPG para encontrar melhores estruturas, quando comparado ao método $A G$ implementado neste trabalho, indica que melhorias na implementação do OPG para redução do tempo de simulação seria de grande utilidade para a área de simulação de aglomerados atômicos ou moleculares.

É possível realizar novas comparações do OPG com um AG que utilize operadores específicos para aglomerados. Os resultados deste trabalho indicam que também seria interessante o desenvolvimento de novos operadores específicos para o método OPG, permitindo novos avanços na área de otimização estrutural de aglomerados atômicos e moleculares e na área de Métodos de Apoio à Decisão. 
6

\section{Referências Bibliográficas}

[1] JOHNSTON, R. L. Evolving better nanoparticles: Genetic algorithms for optimising cluster geometries. Dalton Transactions, n. 22, p. 4193-4207, 2003.

[2] SOLIMAN, S. A. H.; MANTAWY, A. A. H. Modern Optimization Techniques with Applications in Electric Power Systems. Springer, 2011. ISBN 9781461417514.

[3] PACHECO, M. A. C.; VELLASCO, M. M. B. R. Intelligent Systems in Oil Field Development Under Uncertainty. Springer, 2009. ISBN 9783540929994.

[4] HORST, R.; PARDALOS, P. M.; VAN THOAI, N. Introduction to Global Optimization. Springer, 2000. ISBN 9780792367567.

[5] VILELA NETO, O. P. Projeto, Otimização, Simulação e Predição de Propriedades de Nanoestruturas através de Técnicas da Inteligência Computacional: Nanotecnologia Computacional Inteligente. 2009. 166 (Doutorado). Engenharia Elétrica, PUC-Rio, Rio de Janeiro, RJ, Brasil.

[6] BAZTERRA, V. E. et al. Modified genetic algorithms to model cluster structures in medium-size silicon clusters. Physical Review A, v. 69, n. 5, p. 053202, 2004.

[7] HARTKE, B. Global geometry optimization of clusters using genetic algorithms. The Journal of Physical Chemistry, v. 97, n. 39, p. 9973-9976, 1993/09/01 1993. ISSN 0022-3654.

[8] XIAO, Y.; WILLIAMS, D. E. Genetic algorithm: a new approach to the prediction of the structure of molecular clusters. Chemical Physics Letters, v. 215, n. 1-3, p. 17-24, 1993. ISSN 0009-2614.

[9] DOYE, J. P. K.; WALES, D. J.; BERRY, R. S. The effect of the range of the potential on the structures of clusters. The Journal of Chemical Physics, v. 103, n. 10, p. 4234-4249, 1995.

[10] P. K. DOYE, J.; J. WALES, D. Structural consequences of the range of the interatomic potential A menagerie of clusters. Journal of the Chemical Society, Faraday Transactions, v. 93, n. 24, p. 4233-4243, 1997. ISSN 0956-5000. 
[11] SPEARS, W.; AL, E. An Overview of Evolutionary Computation. Proceedings of the European Conference on Machine Learning. SPRINGER-VERLAG. London, UK: 442-459 p. 1993.

[12] MITCHELL, M. An Introduction to Genetic Algorithms. MIT Press, 1998. ISBN 9780262631853.

[13] KOZA, J. R. Genetic Programming: vol. 1 , On the programming of computers by means of natural selection. Bradford, 1992. ISBN 9780262111706.

[14] GOLDBERG, D. E. Genetic Algorithms in Search, Optimization, and Machine Learning. Addison-Wesley, 1989. ISBN 9780201157673.

[15] BACK, T. Evolutionary algorithms in theory and practice: evolution strategies, evolutionary programming, genetic algorithms. Oxford University Press, 1996. 314 ISBN 0-19-509971-0.

[16] FOGEL, L. J.; OWENS, A. J.; WALSH, M. J. Artificial Intelligence Through Simulated Evolution. John Wiley \& Sons, 1966.

[17] MICHALEWICZ, Z. Genetic Algorithms + Data Structures = Evolution Programs. Springer, 1996. ISBN 9783540606765.

[18] LANGDON, W. B.; POLI, R. Foundations of Genetic Programming. Springer, 2002. ISBN 9783540424512.

[19] BANZHAF, W. Genetic Programming: An Introduction : On the Automatic Evolution of Computer Programs and Its Applications. Morgan Kaufman, 1998. ISBN 9781558605107.

[20] PUJOL, J. C. F.; POLI, R. Parameter Mapping: A genetic programming approach to function optimization. International Journal of Knowledge-Based and Intelligent Engineering Systems, v. 12, n. 1, p. 29-45, 2008.

[21] WILLIS, M. J. et al. Genetic Programming an Introduction and Survey of Applications. Genetic Algorithms in Engineering Systems: Innovations and Applications 1997.

[22] POLI, R. et al. A Field Guide to Genetic Programming. Lulu.com, 2008. ISBN 9781409200734.

[23] HINCHLIFFE, M. et al. Modelling Chemical Process Systems Using a Multi-Gene Genetic Programming Algorithm. Late Breaking Papers at the Genetic 
Programming 1996 Conference Stanford University July 28-31, 1996. Stanford University, CA, USA: Stanford Bookstore 1996.

[24] SEARSON, D.; WILLIS, M.; MONTAGUE, G. Co-evolution of non-linear PLS model components. Journal of Chemometrics, v. 21, n. 12, p. 592-603, Dec 2007. ISSN 0886-9383.

[25] KOSHIYAMA, A. S. et al. GPF-CLASS: A Genetic Fuzzy model for classification. Evolutionary Computation (CEC), 2013 IEEE Congress on. 20-23 June 2013, 2013. 3275-3282 p.

[26] . Numerical optimization by multi-gene genetic programming. Proceeding of the fifteenth annual conference companion on Genetic and evolutionary computation conference companion. Amsterdam, The Netherlands: ACM: 145-146 p. 2013.

[27] DOYE, J. P. K. et al. Global Optimization of Morse Clusters by Potential Energy Transformations. INFORMS J. on Computing, v. 16, n. 4, p. 371-379, 2004. ISSN 1526-5528.

[28] ALEXANDROVA, A. N. et al. Structure of the Na[sub $x] C l[\operatorname{sub} x+1]$ [sup -] ( $x=1--$ 4) clusters via ab initio genetic algorithm and photoelectron spectroscopy. The Journal of Chemical Physics, v. 121, n. 12, p. 5709-5719, 2004.

[29] ALEXANDROVA, A. N.; BOLDYREV, A. I. Search for the Lin0/+1/-1 ( $n=5-7)$ Lowest-Energy Structures Using the ab Initio Gradient Embedded Genetic Algorithm (GEGA). Elucidation of the Chemical Bonding in the Lithium Clusters. Journal of Chemical Theory and Computation, v. 1, n. 4, p. 566-580, 2005/07/01 2005. ISSN 1549-9618.

[30] HARTKE, B. Size-dependent transition from all-surface to interior-molecule structures in pure neutral water clusters. Physical Chemistry Chemical Physics, v. 5, n. 2, p. 275-284, 2003. ISSN 1463-9076.

[31] HARTKE, B.; FLAD, H.-J.; DOLG, M. Structures of mercury clusters in a quantumempirical hybrid model. Physical Chemistry Chemical Physics, v. 3, n. 23, p. 5121-5129, 2001. ISSN 1463-9076.

[32] ZEIRI, Y. Prediction of the lowest energy structure of clusters using a genetic algorithm. Physical Review E, v. 51, n. 4, p. R2769-R2772, 1995.

[33] DEAVEN, D. M.; HO, K. M. Molecular Geometry Optimization with a Genetic Algorithm. Physical Review Letters, v. 75, n. 2, p. 288-291, 1995. 
[34] SEARSON, D. Genetic programming symbolic regression for matlab. 2009.

[35] WILCOXON, F. Individual Comparisons by Ranking Methods. Biometrics Bulletin, v. 1, n. 6, p. 80-83, 1945. ISSN 00994987.

[36] MURTEIRA, B. J. F.; BLACK, G. H. J. Estatística descritiva. Lisboa: McGraw-Hill de Portugal, 1983.

[37] $\mathrm{KABSCH}, \mathrm{W}$. A solution for the best rotation to relate two sets of vectors. Acta Crystallographica Section A, v. 32, n. 5, p. 922-923, 1976. ISSN 0567-7394. 
A

\section{Wilcoxon Signed Rank}

O método Wilcoxon Signed Rank [35] busca a comparação entre duas amostras, que geralmente não são provenientes de uma população com distribuição Normal. Portanto, este método é mais utilizado quando o teste de normalidade indica que não há indícios que a população advenha de uma distribuição Normal, ou ainda, quando há claras indicações que esta afirmação é falsa (e.g. quando a variável possui valores ordinais).

A hipótese nula é que os parâmetros de locação das duas amostram não são diferentes, enquanto que a alternativa é de que são. Dependendo da aplicação, estes parâmetros de locação são confundidos com as medianas das amostras. O princípio básico do método é realizar uma transformação na variável original, usando o conceito de ranqueamento (postos). A tabela A.1 apresenta um exemplo.

\begin{tabular}{ccccccc}
\hline \hline$i$ & $x_{2 i}$ & $x_{1 i}$ & $s g n$ & & & \multicolumn{2}{c}{$x_{2 i}-x_{1 i}$} \\
\cline { 5 - 7 } & 140 & 140 & & 0 & $R_{i}$ & $s g n \cdot R_{i}$ \\
\hline 5 & 140 & 125 & 1 & 5 & 1,5 & 1,5 \\
3 & 130 & 1 & 5 & 1,5 & 1,5 \\
9 & 140 & 135 & -1 & 7 & 3 & -3 \\
2 & 115 & 122 & -1 & 9 & 4 & -4 \\
6 & 115 & 124 & -1 & 10 & 5 & -5 \\
10 & 135 & 145 & -1 & 12 & 6 & -6 \\
8 & 125 & 137 & 1 & 15 & 7 & 7 \\
1 & 125 & 110 & 1 & 17 & 8 & 8 \\
7 & 140 & 123 & 1 & 20 & 9 & 9 \\
4 & 140 & 120 & &
\end{tabular}

Tabela A.1. Exemplo do método Wilcoxon Signed Rank.

Considere $x_{2 i}$ e $x_{1 i}$ as duas amostras, onde $i=1, \ldots, 10$ representa a ordem em que as amostras foram inicialmente coletadas. $a b s=\mid x_{2 i}-$ $x_{1 i}$ l é o módulo da diferença entre os valores das i-ésimas amostras. O sgn é o sinal que indica qual das duas amostras obteve maior valor. $R_{i}$ é o ranque (posto) fornecido com relação à magnitude do abs: quanto maior for o $a b s_{i}$ maior será o $R_{i}$. No caso de empates é usado uma média dos possíveis ranques ocupados. Então, calcula-se a estatística de teste $Z$, dada por: 


$$
\begin{gathered}
W=\left|\sum_{i=1}^{n_{r}}\left[\operatorname{sgn}\left(x_{2 i}-x_{1 i}\right) \cdot R_{i}\right]\right| \\
s_{W}=\sqrt{\frac{n_{r}\left(n_{r}+1\right)\left(2 n_{r}+1\right)}{6}} \\
Z=\frac{W-0.5}{s_{W}} \sim Z(0,1)
\end{gathered}
$$

onde $n_{r}$ é o número de ranques. A estatística de teste $Z$ possui uma distribuição aproximadamente Normal Padrão, conforme o número de amostras cresce. Quando $n_{r}>10$, esta já é praticamente uma Normal Padrão.

Um nível de significância gera uma região de decisão para identificar se uma hipótese nula é válida, ou não. Esta dissertação adotou um nível de significância de $5 \%$, por se tratar de um valor utilizado na literatura. 